OPEN ACCESS

Edited by:

Hector Mora Montes, University of Guanajuato, Mexico

Reviewed by:

Rocio Garcia-Rodas, University of Nice Sophia Antipolis,

France

Ricardo Sergio Almeida State University of Londrina, Brazil José Ascención Martínez-Álvarez, University of Guanajuato, Mexico

*Correspondence:

Orla Howe

orla.howe@tudublin.ie

Michael Devereux

michael.devereux@tudublin.ie

Specialty section:

This article was submitted to Fungi and Their Interactions,

a section of the journal

Frontiers in Microbiology

Received: 09 December 2019 Accepted: 04 March 2020 Published: 24 March 2020

Citation:

Gandra RM, McCarron P

Viganor L, Fernandes MF

Kavanagh K, McCann M,

Branquinha MH, Santos ALS,

Howe O and Devereux M (2020)

In vivo Activity of Copper(II),

Manganese(II), and Silver(I) 1,10-Phenanthroline Chelates Against Candida haemulonii Using the Galleria mellonella Model.

Front. Microbiol. 11:470 doi: 10.3389/fmicb.2020.00470

\section{In vivo Activity of Copper(II), Manganese(II), and Silver(I) 1,10-Phenanthroline Chelates Against Candida haemulonii Using the Galleria mellonella Model}

Rafael M. Gandra1,2,3, Pauraic McCarron ${ }^{3}$, Livia Viganor ${ }^{1,3}$, Mariana Farias Fernandes ${ }^{1}$, Kevin Kavanagh ${ }^{4}$, Malachy McCann ${ }^{5}$, Marta H. Branquinha ${ }^{1}$, André L. S. Santos ${ }^{1,2}$, Orla Howe ${ }^{3,6 *}$ and Michael Devereux ${ }^{3 *}$

\footnotetext{
'Laboratório de Estudos Avançados de Microrganismos Emergentes e Resistentes, Departamento de Microbiologia Geral, Instituto de Microbiologia Paulo de Góes, Universidade Federal do Rio de Janeiro, Rio de Janeiro, Brazil, ${ }^{2}$ Instituto de Química, Programa de Pós-Graduação em Bioquímica, Universidade Federal do Rio de Janeiro, Rio de Janeiro, Brazil, ${ }^{3}$ Centre for Biomimetic and Therapeutic Research, Focas Research Institute, Technological University Dublin, Dublin, Ireland, ${ }^{4}$ Department of Biology, Maynooth University, National University of Ireland, Maynooth, Ireland, ${ }^{5}$ Department of Chemistry, Maynooth University, National University of Ireland, Maynooth, Ireland, ${ }^{6}$ School of Biological \& Health Sciences,

Technological University Dublin, Dublin, Ireland
}

Candida haemulonii is an emerging opportunistic pathogen resistant to most antifungal drugs currently used in clinical arena. Metal complexes containing 1,10-phenanthroline (phen) chelating ligands have well-established anti-Candida activity against different medically relevant species. This study utilized larvae of Galleria mellonella, a widely used model of in vivo infection, to examine C. haemulonii infection characteristics in response to different copper(II), manganese(II), and silver(I) chelates containing phen, which had demonstrated potent anti-C. haemulonii activity in a previous study. The results showed that $C$. haemulonii virulence was influenced by inoculum size and incubation temperature, and the host $G$. mellonella immune response was triggered in an inoculum-dependent manner reflected by the number of circulating immune cells (hemocytes) and observance of larval melanization process. All test chelates were non-toxic to the host in concentrations up to $10 \mu \mathrm{g} /$ larva. The complexes also affected the G. mellonella immune system, affecting the hemocyte number and the expression of genes encoding antifungal and immune-related peptides (e.g., inducible metalloproteinase inhibitor protein, transferrin, galiomycin, and gallerimycin). Except for $\left.\left[\mathrm{Ag}_{2} \text { (3,6,9-tdda)(phen) }\right)_{4}\right]$.EtOH (3,6,9-tddaH $\mathrm{H}_{2}=$ 3,6,9-trioxoundecanedioic acid), all chelates were capable of affecting the fungal burden of infected larvae and the virulence of $C$. haemulonii in a dose-dependent manner. This work shows that copper(II), manganese(II), and silver(I) chelates containing phen with anti-C. haemulonii activity are capable of (i) inhibiting fungal proliferation during in vivo infection, (ii) priming an immune response in the $G$. mellonella host and (iii) affecting $C$. haemulonii virulence.

Keywords: Candida haemulonii, metal-1,10-phenanthroline chelates, Galleria mellonella, antifungal activity, immunomodulation 


\section{INTRODUCTION}

Invasive fungal infections have emerged as a significant global health problem with rising fungemia incidences associated with excessive morbidity and mortality (Castelli et al., 2014; Hamdy et al., 2016; Benedict et al., 2017). Candida is the most common fungal etiologic agent of blood infections (candidemia) related to vascular catheters, and is associated with mortality rates of approximately $35 \%$ and an impact of US\$ 8 billion to the United States health-care system every year (World Health Organization, 2014). Invasive candidiasis affects more than a quarter of a million patients annually worldwide, and a candidemia incidence of 2-14 per 100,000 inhabitants in population-based studies have been described (Arendrup and Patterson, 2017). It is also problematic that recent data have demonstrated a shift on infections toward non-albicans Candida species that are more resistant to the available antifungal drugs (Arendrup and Patterson, 2017). This new and unsettling reality led the WHO to aim at establishing an operational framework to create a surveillance network for antifungal resistance as part of the previous established Global Antimicrobial Resistance Surveillance System (GLASS) (World Health Organization, 2019). Among such new resistant emerging opportunistic fungi is the Candida haemulonii complex (C. haemulonii, Candida haemulonii var. vulnera, and Candida duobushaemulonii) (Cendejas-Bueno et al., 2012; Kullberg and Arendrup, 2015). These species are highly resistant to azoles and polyenes, which are the most commonly prescribed antifungal drugs. C. haemulonii species are usually sensitive to echinocandins, a class of antifungal drugs acting on the inhibition of $\beta$-1,3-glucan synthase, which is a key enzyme for integrity of the fungal cell wall. However, reports of clinical isolates resistant to micafungin and of therapeutic failure with caspofungin have been cited (Khan et al., 2007; Kim et al., 2009; Muro et al., 2012). Such characteristics of the $C$. haemulonii species complex are a huge clinical threat and finding new compounds that are effective against such species is urgently required.

Transition metal chelates containing 1,10-phenantroline (phen) ligands have been shown to possess anti-Candida activity against species such as Candida albicans, Candida glabrata, Candida Tropicalis, and C. krusei (Geraghty et al., 2000; McCann et al., 2000, 2012; Coyle et al., 2003). These compounds affect mitochondrial function, reduce cytochrome $b$ and $c$ synthesis, induce respiratory uncoupling and increase cell wall permeability of Candida cells (McCann et al., 2004; Creaven et al., 2007). We have previously demonstrated that copper(II)-, manganese(II)-, and silver(I)-phen chelates are highly efficient against the C. haemulonii complex on both planktonic- and biofilm-growing cells (Gandra et al., 2017). These previous results stimulated the in vivo studies using Galleria mellonella larvae described herein, to further elucidate the hypothesis that such chelates could be potential alternative, metal-based drugs for treating $C$. haemulonii infections. The in vivo G. mellonella model has no ethical issues, is inexpensive and easy to manipulate and maintain. Most importantly, the innate immune system of G. mellonella possess several similarities with humans such as the similar lectin-mediated phagocytic mechanisms between hemocytes and neutrophils, respectively, identical cell surface receptors such as 3-glucan, identical signaling cascades of immune deficiency (IMD), c-Jun $\mathrm{N}$-terminal kinases (JNK) and the Janus kinase/signal transducers and activators of transcription (JAK-STAT) pathways as well as nuclear factor-kappa B (NFkB) and IkB kinase transcription factors modulation by the toll and IMD pathways in the larvae and by the toll-like receptors and tumor necrosis factor alpha (TNF- $\alpha$ ) in mammals (Browne et al., 2013; Wu et al., 2016). Moreover, a strong correlation involving microbial virulence and toxicity of novel antimicrobials between the G. mellonella and mammalian models has been established (Chamilos et al., 2007; Wang et al., 2013; Kavanagh and Sheehan, 2018). Therefore, the G. mellonella model has been widely used to assess the virulence of microbial pathogens and it was optimized to increase susceptibility to bacterial and fungal infections for testing the in vivo activity of antimicrobial agents (Kavanagh and Sheehan, 2018), which directly influenced our choice for this model in the current study. Corroborating these findings, recently, we showed that G. mellonella offered a simple and feasible model to study C. haemulonii complex virulence and drug efficacy, in which the first-line antifungals (fluconazole, amphotericin B, and caspofunfin) were tested with equivalent therapeutic doses and minimal inhibitory concentrations (MIC) profile in vitro was correlated with in vivo antifungal efficacy (Silva et al., 2018).

Herein, we further evaluate the chemotherapeutic potential of one copper(II)-, seven manganese(II)-, and three silver(I)-chelates containing the phen ligand toward the treatment of infections caused by a clinical isolate of C. haemulonii using the in vivo model, G. mellonella. We have investigated the virulence of the strain, how it affects the host immune system, how the chelates affect the ability of the fungal cells to infect a host and how the metal-chelates interfere with the larvae immune response.

\section{MATERIALS AND METHODS}

\section{C. haemulonii Strain}

Candida haemulonii (LIP Ch4) isolated in the hospital service of Universidade Federal Fluminense (obtained from a fingernail) was used during this study. The antifungal susceptibility profile of the strain was previously described, being resistant to azoles and polyenes (Ramos et al., 2015; Silva et al., 2018). For all assays, fungal cells were incubated in Sabouraud dextrose culture medium for $48 \mathrm{~h}$ at $37^{\circ} \mathrm{C}$ under constant agitation $(130 \mathrm{rpm})$. After culture, cells were centrifuged at $5,000 \times g$ for $5 \mathrm{~min}$, washed in sodium phosphate buffer (PBS; $\mathrm{NaCl} 150 \mathrm{mM}$, phosphate buffer $20 \mathrm{mM}, \mathrm{pH}$ 7.2) and cells estimated using a Neubauer chamber.

\section{Galleria mellonella Larvae}

The larvae of the greater wax moth G. mellonella were purchased from Livefoods (Livefoods Direct, United Kingdom) and kept in 
wood shavings at $15^{\circ} \mathrm{C}$ in the dark. Larvae weighing between 0.2 and $0.3 \mathrm{~g}$ with no color alterations were selected for all experiments and used in groups of 10 per experimental parameter for mortality and 3 for hemocyte extractions (Bergin et al., 2003).

\section{Metal Chelates}

The metal chelates used during this study were prepared following previously published methods (Casey et al., 1994; McCann et al., 1997, 2004; Devereux et al., 2000; Leon, 2000; Gandra et al., 2017) and are summarized in Table 1.

\section{Effects of the Metal Chelates on C. haemulonii: Fungicidal and Fungistatic Activity}

Candida haemulonii was inoculated in a 96-well plate $\left(10^{6}\right.$ cells/well) containing $200 \mu \mathrm{L}$ of culture medium and the chelates with concentrations ranging from 2 to $0.125 \mathrm{mg} / \mathrm{L}$. Plates were incubated at $37^{\circ} \mathrm{C}$ for $24 \mathrm{~h}$ and the contents of each well collected in Eppendorf tubes and centrifuged at 12,000 $g$ for $2 \mathrm{~min}$. The supernatant was discarded, the cell pellet re-suspended in PBS and cellular density was established by direct count in a Neubauer chamber. The chelate concentration capable of reducing cellular density by $50 \%$ was established by plotting the number of viable cells vs. the drug concentration log using the Origin Pro 7.5 software. The microdilution protocol described in the document, M27-A3 published by the Clinical Laboratory Standards Institute, was used for the fungicidal vs. fungistatic activity analysis (CLSI, 2008). C. haemulonii ( $10^{6}$ cells/well) was inoculated into a 96well plate containing the chelates in concentrations ranging from 0.0625 to $32 \mathrm{mg} / \mathrm{L}$ and plates were incubated for $48 \mathrm{~h}$ at $37^{\circ} \mathrm{C}$. After that, an aliquot of $50 \mu \mathrm{l}$ from each well with no visible growth was inoculated into agar Sabouraud plates, which were incubated for $48 \mathrm{~h}$ at $37^{\circ} \mathrm{C}$. The plates where visible colonies were present were considered as a fungistatic chelate concentration, while complete absence of colonies were designated a fungicidal concentration.

TABLE 1 | Copper(II) (1), manganese(II) (2-8), and silver(I) (9-11) chelates.

\begin{tabular}{|c|c|c|}
\hline Chelate & Formula & Synthesis references \\
\hline 1 & $\left\{\left[\mathrm{Cu}(3,6,9 \text {-tdda })(\text { phen })_{\mathbf{2}}\right] \cdot 3 \mathrm{H}_{\mathbf{2}} \mathrm{O} \cdot \mathrm{EtOH}\right\}_{\mathbf{n}}$ & Gandra et al., 2017 \\
\hline 2 & {$\left[\mathrm{Mn}(\mathrm{ph})(\mathrm{phen})\left(\mathrm{H}_{2} \mathrm{O}\right)_{2}\right]$} & Devereux et al., 2000 \\
\hline 3 & {$\left[\mathrm{Mn}(\mathrm{ph})(\mathrm{phen})_{2}\left(\mathrm{H}_{2} \mathrm{O}\right)\right] \cdot 4 \mathrm{H}_{2} \mathrm{O}$} & Devereux et al., 2000 \\
\hline 4 & {$\left[\mathrm{Mn}_{2}(\text { isoph })_{2}(\text { phen })_{3}\right] \cdot 4 \mathrm{H}_{2} \mathrm{O}$} & Devereux et al., 2000 \\
\hline 5 & $\left\{\left[\mathrm{Mn}(\text { phen })_{2}\left(\mathrm{H}_{2} \mathrm{O}\right)_{2}\right]\right\}_{2}$ (isoph) $)_{2}$ (phen). $12 \mathrm{H}_{2} \mathrm{O}$ & Devereux et al., 2000 \\
\hline 6 & {$\left[\mathrm{Mn}(\right.$ tereph$\left.)(\text { phen })_{2}\right] .5 \mathrm{H}_{2} \mathrm{O}$} & Leon, 2000 \\
\hline 7 & $\begin{array}{l}{\left[\mathrm{Mn}_{2}(\text { oda })(\text { phen })_{4}\left(\mathrm{H}_{2} \mathrm{O}\right)_{2}\right]\left[\mathrm{Mn}_{2}(\text { oda })(\text { phen })_{4}\right.} \\
\left.\text { (oda) })_{2}\right] \cdot 4 \mathrm{H}_{2} \mathrm{O}\end{array}$ & Casey et al., 1994 \\
\hline 8 & $\left\{\left[\mathrm{Mn}(3,6,9 \text {-tdda })(\text { phen })_{2}\right] \cdot 3 \mathrm{H}_{2} \mathrm{O} \cdot \mathrm{EtOH}\right\}_{\mathrm{n}}$ & McCann et al., 1997 \\
\hline 9 & {$\left[\mathrm{Ag}(\text { phendione })_{2}\right] \mathrm{ClO}_{4}$} & McCann et al., 2004 \\
\hline 10 & {$\left[\mathrm{Ag}_{\mathbf{2}}(3,6,9-\mathrm{tdda})(\text { phen })_{4}\right] \cdot \mathrm{EtOH}$} & Gandra et al., 2017 \\
\hline 11 & {$\left[\mathrm{Ag}(\text { phen })_{2}\right] \mathrm{ClO}_{4}$} & McCann et al., 2004 \\
\hline
\end{tabular}

3,6,9-tddaH $\mathrm{H}_{2}$, 3,6,9-trioxaundecanedioic acid; $\mathrm{phH}_{2}$, phthalic acid; isoph $\mathrm{H}_{2}$, isophthalic acid; tereph $\mathrm{H}_{2}$, terephthalic acid; $\mathrm{odaH}_{2}$, octanedioic acid; phen, 1,10-phenanthroline; phendione, 1,10-phenanthroline-5,6-dione.

\section{Fungal Infection of Galleria mellonella Larvae}

The infection profile was assessed using a previously described methodology (Desbois and Coote, 2012; Kavanagh and Sheehan, 2018). C. haemulonii cells were suspended in PBS in the following concentrations: $5 \times 10^{4}, 5 \times 10^{5}, 5 \times 10^{6}, 5 \times 10^{7}$, and $5 \times 10^{8}$ cells $/ \mathrm{mL}$. Using a Myjector syringe (23 gauge; BD PrecisionGlide), 10 larvae were inoculated through the last left pro-leg with $20 \mu \mathrm{l}$ of the cell suspensions, with final concentrations of $10^{3}, 10^{4}, 10^{5}, 10^{6}$, and $10^{7}$ fungal cells/larvae, which were injected directly into the hemocoel. Untouched larvae and larvae inoculated with $20 \mu \mathrm{L}$ of sterile PBS were used as controls. The larvae were placed in sterile petri dishes containing $9 \mathrm{mM}$ filter paper and wood shavings and incubated at 30 or $37^{\circ} \mathrm{C}$ for up to 9 days, and the mortality rate was evaluated every $24 \mathrm{~h}$ post-infection. For virulence comparison purposes, a C. albicans strain (ATCC 10231) was used under the same conditions. Death was determined by melanization and lack of movement after stimulation with a needle (Barnoy et al., 2017).

\section{Fungal Burden}

Larvae were inoculated with different $C$. haemulonii concentrations ranging from $10^{3}$ to $10^{7}$ cells per larvae. The infected models were incubated at $30^{\circ} \mathrm{C}$, and after 6,24 , and $48 \mathrm{~h}$ of infection 3 larvae were randomly selected and washed in ethanol $70 \%$. After drying, the larvae were cut into small pieces using a sterile scalpel and added to $15 \mathrm{~mL}$ falcon tubes containing $1 \mathrm{~mm}$ glass beads $(1 \mathrm{~g})$ and $1 \mathrm{~mL}$ of PBS + ampicillin $(1 \mathrm{mg} / \mathrm{L})$. The tubes were vortexed for $10 \mathrm{sec}$, and $100 \mu \mathrm{L}$ of each sample was collected and serially diluted. The dilutions were plated $(50 \mu \mathrm{L})$ onto Sabouraud plates containing chloramphenicol $(100 \mathrm{mg} / \mathrm{L})$. The plates were incubated during $48 \mathrm{~h}$ at $30^{\circ} \mathrm{C}$ and the number of colony forming units (CFU) were counted.

\section{G. mellonella Immune Response to Fungal Infection}

Larvae were inoculated with different $C$. haemulonii concentrations ranging from $10^{3}$ to $10^{7}$ cells per larvae. The infected models were incubated at $30^{\circ} \mathrm{C}$, and after 6,24 , and $48 \mathrm{~h}$ of infection 3 larvae were randomly selected and the haemolymph extracted (2-3 drops) by piercing the back of the anterior end with a sterile needle. To prevent clotting and melanization, the haemolymph was collected into a prechilled Eppendorf and $30 \mu \mathrm{L}$ were transferred into a 1 in 10 solution of cold PBS containing $0.37 \%$ (v/v) 2-mercaptoethanol (Sigma-Aldrich) (Kelly and Kavanagh, 2011). After gentle homogenization, $10 \mu \mathrm{L}$ of the solution were transferred to a Neubauer chamber and the hemocytes number counted under a microscope. Three different counts were performed for each sample and the cell number multiplied by the dilution factor of the haemolymph (10) and the hemocytometer (50.000) in order to determine cellular density. 


\section{G. mellonella Larvae Response to Metal-Chelates}

\section{Metal-Chelate Toxicity and Effect on G. mellonella Immune Response}

Each chelate solution was diluted in dimethyl sulfoxide (DMSO) or sterile water in concentrations of 1,500, 750, 500, 200, and $100 \mathrm{mg} / \mathrm{L}$. Using a Myjector syringe (23 gauge; BD PrecisionGlide), groups of 10 larvae were inoculated with $20 \mu \mathrm{L}$ of the diluted working solutions, resulting in final test concentrations of $30,15,10,4$, and $2 \mu \mathrm{g} /$ larva. Untouched larvae, larvae inoculated with DMSO equivalent to the highest concentration present in the dilutions (2\%) and larvae inoculated with $20 \mu \mathrm{L}$ of sterile PBS were used as controls. The injected samples were placed in sterile petri dishes containing $9 \mathrm{mM}$ filter paper and wood shaves and incubated at $30^{\circ} \mathrm{C}$ for $72 \mathrm{~h}$ and mortality rate was evaluated every $24 \mathrm{~h}$. For the immunomodulation assays, groups of 10 larvae were inoculated with 15 and $30 \mu \mathrm{g} /$ larvae of the chelates and incubated for $24 \mathrm{~h}$ as previously described. After this period, 3 random larvae were chosen, the haemolymph extracted and hemocytes density established as described above (Kelly and Kavanagh, 2011).

\section{Metal-Chelate Influence Over Expression of Relevant Antimicrobial Peptides}

\section{Target genes and primer sequences}

Primer sets (Forward and Reverse sequences) for target and reference genes were obtained from Sigma Genosys. Table 2 indicates the primer sequences for the gene $S 7 e$, a housekeeping gene that encodes the ribosomal protein S7e and the 4 target genes associated with the G. mellonella immune response, namely transferrin, IMPI, galiomicin, and Gallerimycin. In the analysis of each target gene, it was normalized to the reference gene.

\section{RNA extraction of G. mellonella exposed to metal chelates}

Groups of 10 larvae were exposed to the highest concentration in which none of the chelates induced mortality (10 $\mu \mathrm{g} /$ larvae) by inoculation directly into the larvae haemolymph as previously described. All workspace and equipment were previously treated with RNase Away (Molecular Bioproduct). After 24 h, 3 larvae were randomly chosen and immersed in liquid nitrogen in a sterile mortar and ground-up with a sterile pestle into a fine powder. The mortar was allowed to warm for a few minutes and $1 \mathrm{~mL}$ of Tri-reagent (Sigma-Aldrich) was added and the resulting mixture was gently transferred to an Eppendorf. The sample was allowed to stand for $2 \mathrm{~min}$ before being centrifuged at 2,000 $\mathrm{g}$ for $2 \mathrm{~min}$ and the supernatant was transferred to a new Eppendorf while the pellet was discarded. The samples were either stored at $-80^{\circ} \mathrm{C}$ or immediately used. To extract the RNA, samples were thawed and gently inverted and chloroform (Sigma-Aldrich) was added to the tubes. After $5 \mathrm{~min}$ the samples were centrifuged for $15 \mathrm{~min}$ at $12,000 \mathrm{~g}$ at $4^{\circ} \mathrm{C}$ to separate it into 3 distinct phases. The upper phase (clear) containing the RNA was carefully transferred to a separate Eppendorf. Propan-2-ol (Sigma) $(0.5 \mathrm{~mL})$ was added and the tubes were gently inverted and incubated at room temperature for $10 \mathrm{~min}$ and then centrifuged at $4^{\circ} \mathrm{C}$ for $10 \mathrm{~min}$ at $12,000 \mathrm{~g}$. The supernatant was removed and the RNA pellet was washed once with $1 \mathrm{~mL}$ of $75 \%$ ethanol (Sigma) and then re-suspended in $30 \mu \mathrm{L}$ of $0.1 \%$ dietyl pyrocarbonate (DEPC) treated water. The purity and concentration of the RNA samples was measured using the MaestroNano ${ }^{\mathrm{TM}}$ spectrophotometer (MaestroGen, United States). After an initial blank with $0.1 \%$ DEPC treated water, the absorbance ratios (A260/A280 and A260/A230) of the samples were recorded. The samples were then stored at $-80^{\circ} \mathrm{C}$.

\section{Real-Time, One-step quantitative RT-PCR}

Real-Time, One-step RT-PCR was performed in triplicate using a QuantiFast SYBR Green RT-PCR Kit (Qiagen, United Kingdom) following the manufactures guidelines. The reactions were carried out in a $25 \mu \mathrm{L}$ total volume containing $100 \mathrm{ng}$ of total RNA and $1 \mu \mathrm{M}$ final concentration for each forward and reverse primer in a 96-well plate. Each plate contained negative controls (without RNA or without RT mix). The plates were sealed and centrifuged at $1,200 \mathrm{~g}$ for $2 \mathrm{~min}$ before being placed in a 7,500 Fast Real-Time PCR System (Applied Biosystems, Foster City, CA, United States). The Real-Time cycler conditions included 10 min RT reaction at $50^{\circ} \mathrm{C}$ and 5 min PCR initial activation step for $5 \mathrm{~min}$ at $95^{\circ} \mathrm{C}$, followed by 40 cycles of denaturation during $10 \mathrm{~s}$ at $95^{\circ} \mathrm{C}$ and $30 \mathrm{~s}$ of combined annealing/extension at $60^{\circ} \mathrm{C}$. After that, melting-curve analysis were performed to confirm RTPCR specificities. The relative expression was calculated using the $2^{-\Delta \Delta \mathrm{Ct}}$ method, and the $C \mathrm{t}$ values of all immune-related genes analyzed were normalized against the expression of the S7e reference gene.

\section{Metal-Chelates Treatment Effect Over Fungal Burden on G. mellonella Infected With C. haemulonii and Pre-treatment Effect Over Mortality}

Groups of 10 larvae of G. mellonella were inoculated with $5 \times 10^{5}$ cells of C. haemulonii per larvae as previously described. After $1 \mathrm{~h}$ post-inoculation, the larva were treated with the chelates

TABLE 2 | Forward (F) and reverse (R) sequences of genes analyzed.

\section{Primer name}

S7e F S7e R

Transferrin F Transferrin $\mathrm{R}$

IMPI F IMPI R

Galiomicin F Galiomicin R

Gallerimycin F Gallerimycin R

\section{Oligonucleotides $\left(5^{\prime}-3^{\prime}\right)$}

ATGTGCCAATGCCCAGTTG GTGGCTAGGCTTGGGAAGAAT

CCCGAAGATGAACGATCAC CGAAAGGCCTAGAACGTTTG

ATTTGTAACGGTGGACACGA CGCAAATTGGTATGCATGG

CCTCTGATTGCAATGCTGAGTG GCTGCCAAGTTAGTCAACAGG

GAAGATCGCTITCATAGTCGC TACTCCTGCAGTTAGCAATGC
Fragment size [base pair (bp)]

131

535

409

359

175

The housekeeping gene S7e was used as reference. 
in different concentrations $(5,2.5,1.25$, and $0.625 \mu \mathrm{g} / \mathrm{larva})$. Untouched larvae, larvae inoculated with PBS and larvae infected with $C$. haemulonii but not treated were used as a control. The samples were then incubated at $30^{\circ} \mathrm{C}$, and the resulting fungal burden analyzed after 24 and $48 \mathrm{~h}$ of infection. For the fungal burden analysis, 3 larvae were randomly selected and washed in ethanol $(70 \% \mathrm{v} / \mathrm{v})$. After they had dried up, the larvae were cut into small pieces using a sterile scalpel and added to $15 \mathrm{~mL}$ falcon tubes containing $1 \mathrm{~mm}$ glass beads ( $1 \mathrm{~g})$ and $1 \mathrm{~mL}$ of PBS + ampicillin $(1 \mathrm{mg} / \mathrm{L})$. The tubes were vortexed for $10 \mathrm{~s}$ and samples were diluted up to $100.000 \times$. Diluted samples were plated $(50 \mu \mathrm{L})$ into Sabouraud plates containing chloramphenicol $(100 \mathrm{mg} / \mathrm{L})$. The plates were incubated for $48 \mathrm{~h}$ at $30^{\circ} \mathrm{C}$ and the number of $\mathrm{CFU}$ were counted (Mesa-Arango et al., 2013). For the pre-treatment impact over virulence assays, $C$. haemulonii cells $\left(5 \times 10^{6}\right)$ were incubated in Sabouraud broth containing the chelates in two different sub-inhibitory concentrations (1/2 and $1 / 4$ of the $\mathrm{IC}_{50}$ value) for $24 \mathrm{~h}$ at $37^{\circ} \mathrm{C}$. After the exposition period, the tubes were centrifuged at $14,000 \mathrm{~g}$ for $2 \mathrm{~min}$ and cells were washed twice in PBS, being resuspended in $20 \mu \mathrm{L}$ of PBS and inoculated into the larvae as previously described, with mortality being assessed after 24 and 48 h postinfection.

\section{Statistical Analysis}

All experiments were performed in triplicate, in three independent experimental sets. Data were analyzed statistically by means of Student's $t$-test using the GraphPad Prism version 5.00 for Windows, GraphPad Software (La Jolla, CA, United States). In all analyses, $P$-values of 0.05 or less were considered statistically significant.

\section{Ethics Statement}

An ethics statement is not necessary. The clinical isolate was not obtained directly from a patient. The sample was received anonymized, without the name or any personal information from the source. No vertebrates or higher vertebrate animals were used during the study.

\section{RESULTS}

\section{Metal-Chelate IC $_{50}$ Values and Fungistatic/Fungicidal Activity}

The $\mathrm{IC}_{50}$ values of $C$. haemulonii exposed to the chelates (Table 3) ranged between 0.36 and $1.07 \mathrm{mg} / \mathrm{L}$. Silver(I) chelates had better activity in general, with values ranging between 0.36 and $0.77 \mathrm{mg} / \mathrm{L}$, while manganese(II) chelates had $\mathrm{IC}_{50}$ values ranging between 0.55 and $1.07 \mathrm{mg} / \mathrm{L}$. Fungicidal activity occurred in concentrations ranging from $\geq 4$ to $32 \mathrm{mg} / \mathrm{L}$ for manganese(II), $\geq 1$ to $\geq 8$ for silver(I) chelates, and of $\geq 8$ for the copper(II) chelate. The best fungicidal activity was observed for the silver(I) chelates 9 and 11. The manganese(II) chelate, 6 , on the other hand, only demonstrated fungicidal activity at $32 \mathrm{mg} / \mathrm{L}$.
TABLE 3 | IC 50 and fungicidal concentration values for $C$. haemulonii exposed to metal chelates.

\begin{tabular}{|c|c|c|}
\hline Metal chelate & $\begin{array}{c}\mathrm{IC}_{50} \\
(\mathrm{mg} / \mathrm{L})\end{array}$ & $\begin{array}{c}\text { Fungicidal }^{\mathrm{a}} \\
(\mathrm{mg} / \mathrm{L})\end{array}$ \\
\hline$\left\{\left[\mathrm{Cu}(3,6,9-\mathrm{tdda})(\text { phen })_{2}\right] 3 \mathrm{H}_{2} \mathrm{O} \cdot \mathrm{EtOH}\right\}_{\mathrm{n}}$ (1) & $0.52 \pm 0.08$ & 8 \\
\hline$\left[\mathrm{Mn}(\mathrm{ph})(\right.$ phen $\left.)\left(\mathrm{H}_{2} \mathrm{O}\right)_{2}\right](2)$ & $0.96 \pm 0.23$ & 8 \\
\hline$\left[\mathrm{Mn}(\mathrm{ph})(\text { phen })_{2}\left(\mathrm{H}_{2} \mathrm{O}\right)\right] 4 \mathrm{H}_{2} \mathrm{O}(3)$ & $0.78 \pm 0.18$ & 4 \\
\hline$\left.\left[\mathrm{Mn}_{2} \text { (isoph }\right)_{2}(\text { phen })_{3}\right] 4 \mathrm{H}_{2} \mathrm{O}(4)$ & $0.69 \pm 0.01$ & 16 \\
\hline$\left\{\left[\mathrm{Mn}(\text { phen })_{2}\left(\mathrm{H}_{2} \mathrm{O}\right)_{2}\right]\right\}_{2}$ (isoph $)_{2}$ (phen). $12 \mathrm{H}_{2} \mathrm{O}$ (5) & $1.07 \pm 0.24$ & 8 \\
\hline$\left[\mathrm{Mn}(\text { tereph)(phen) })_{2}\right] 5 \mathrm{H}_{2} \mathrm{O}(6)$ & $0.59 \pm 0.10$ & 32 \\
\hline $\begin{array}{l}{\left[\mathrm{Mn}_{2}(\text { oda })(\text { phen })_{4}\left(\mathrm{H}_{2} \mathrm{O}\right)_{2}\right]\left[\mathrm{Mn}_{2}(\text { oda })\right.} \\
\left.\text { (phen })_{4}(\text { oda })_{2}\right] 4 \mathrm{H}_{2} \mathrm{O}(7)\end{array}$ & $0.55 \pm 0.03$ & 8 \\
\hline$\left\{\left[\mathrm{Mn}(3,6,9-\mathrm{tdda})(\text { phen })_{2}\right] 3 \mathrm{H}_{2} \mathrm{O} \cdot \mathrm{EtOH}\right\}_{\mathrm{n}}(8)$ & $0.65 \pm 0.10$ & 4 \\
\hline$\left[\mathrm{Ag}(\text { phendione })_{2}\right] \mathrm{ClO}_{4}(9)$ & $0.77 \pm 0.02$ & 2 \\
\hline$\left[\mathrm{Ag}_{2}(3,6,9 \text {-tdda)(phen) })_{4}\right] \cdot \mathrm{EtOH}(10)$ & $0.39 \pm 0.07$ & 8 \\
\hline$\left[\mathrm{Ag}(\text { phen })_{2}\right] \mathrm{ClO}_{4}(11)$ & $0.36 \pm 0.08$ & 1 \\
\hline
\end{tabular}

avalues reflect concentrations at which no cell growth was detected in the wells after visual inspection and after the sample being plated into sabouraud agar and incubated for $48 \mathrm{~h}$.

\section{C. haemulonii Virulence to G. mellonella}

Larvae infected with $C$. haemulonii and with $C$. albicans under the same conditions and incubated at 30 or $37^{\circ} \mathrm{C}$ were used in this assay (Figures 1, 2). Larvae infected with $10^{3}-10^{5}$ fungal cells/larvae had a small mortality rate after 5 days of incubation, but with no statistical relevance when compared to the control inoculated only with PBS. The inoculum of $10^{6}$ cells/larvae of C. albicans induced mortality rates of $28 \%$ after $24 \mathrm{~h}$ and 53, 65, 82, and $90 \%$ on the following days at $30^{\circ} \mathrm{C}$. In contrast, the systems incubated at $37^{\circ} \mathrm{C}$ demonstrated mortality rates of 83,85 , and $95 \%$ after 24,48 , and $72 \mathrm{~h}$ post-infection, respectively. At all analysis points, mortality was statistically significant when compared with the PBS-inoculated control ( $p<0.05$, student $t$-test). The $10^{7}$ cells/larva inoculum caused $100 \%$ mortality after $24 \mathrm{~h}$ at both temperatures. Regarding C. haemulonii, mortality in larvae infected with $10^{6}$ cells and incubated at $30^{\circ} \mathrm{C}$ was observed after 3 days, which gradually increased and was statistically significant after 8 days $(30 \%$ mortality) when compared with the PBS-inoculated control. Larvae incubated at $37^{\circ} \mathrm{C}$ only demonstrated mortality after 6 days, but with no statistical relevance when compared with the PBS-inoculated control. When the inoculum was increased to $10^{7}$ cells/larvae, animals incubated at $30^{\circ} \mathrm{C}$ had mortality rates of $82 \%$ after $24 \mathrm{~h}$, increasing to 97 and $100 \%$ after $48 \mathrm{~h}$ and $72 \mathrm{~h}$, respectively. Systems incubated at $37^{\circ} \mathrm{C}$ had mortality rates of $13 \%$ after $24 \mathrm{~h}$, progressively increasing to 18,55 , 63,83 , and $88 \%$ each day. After 9 days, fungal inoculums of $10^{3}$ to $10^{5}$ cells/larvae of both species were not capable of significantly affecting the larvae mortality. C. albicans induced mortality rates of $98 \%\left(10^{6}\right.$ inoculum $)$ and $100 \%\left(10^{7}\right)$ at both 30 and $37^{\circ} \mathrm{C}$. The C. haemulonii $10^{6}$ inoculum only induced statistically relevant mortality at $30^{\circ} \mathrm{C}(60 \%)$, while the inoculum of $10^{7}$ cells/larvae resulted in mortality rates of $100 \%$ at $30^{\circ} \mathrm{C}$ and $88 \%$ at $37^{\circ} \mathrm{C}$. In the control systems (PBS-inoculated), mortality rates of $30 \%$ were observed at $37^{\circ} \mathrm{C}$ and of $12 \%$ at $30^{\circ} \mathrm{C}$. 

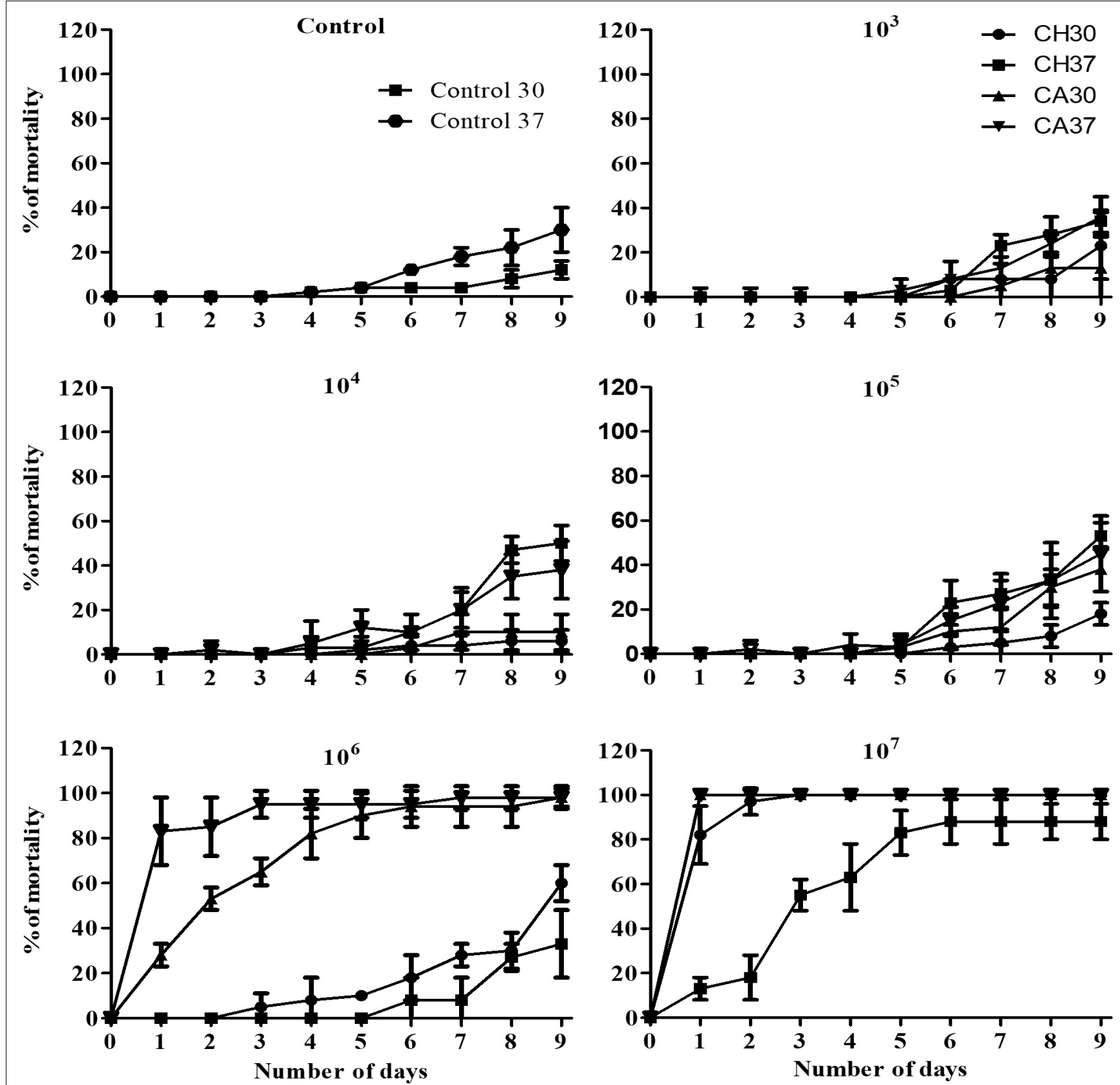

FIGURE 1 | Evaluation of the virulence of Candida haemulonii and temperature effect over pathogenesis on Galleria mellonella. Candida Haemulonii, and Candida albicans cells incubated at $37^{\circ} \mathrm{C}$ for $48 \mathrm{~h}$ were harvested and inoculated into groups of 10 larvae of $\mathrm{G}$. mellonella in different concentrations $\left(10^{3}-10^{7} \mathrm{cells} / \mathrm{larvae}\right)$. Infected larvae were incubated at 30 or $37^{\circ} \mathrm{C}$ for up to 9 days and mortality assessed every $24 \mathrm{~h} . \mathrm{CH} 30, \mathrm{C}$. haemulonii $30^{\circ} \mathrm{C} ; \mathrm{CA} 30, \mathrm{C}$. albicans $30^{\circ} \mathrm{C} ; \mathrm{CH} 37$, C. haemulonii $37^{\circ} \mathrm{C} ; \mathrm{CA} 37, \mathrm{C}$. albicans $37^{\circ} \mathrm{C}$. Larvae inoculated with PBS were used as control. Mortality was determined by lack of movement after stimulation with a needle and also by melanization.

\section{Melanization Process in Infected Larvae}

No cuticle color alterations were observed in C. haemulonii larvae inoculate with $10^{3}$ and $10^{4}$ cells/larvae (Figures 3A,B). The $10^{5}$ inoculum resulted in small-darkened areas around the needle insertion area (Figure 3C). Larvae infected with $10^{6}$ cells had more pronounced alterations, with larger darkened areas observable (Figure 3D). An intense and disseminated melanization process was observed in larvae infected with the $10^{7}$ inoculum (Figure 3E).

\section{Fungal Burden Determination in}

\section{G. mellonella}

Fungal burden in larvae infected with $10^{3} \mathrm{C}$. haemulonii cells remained stable between the 6 and $24 \mathrm{~h}$ analysis points, 

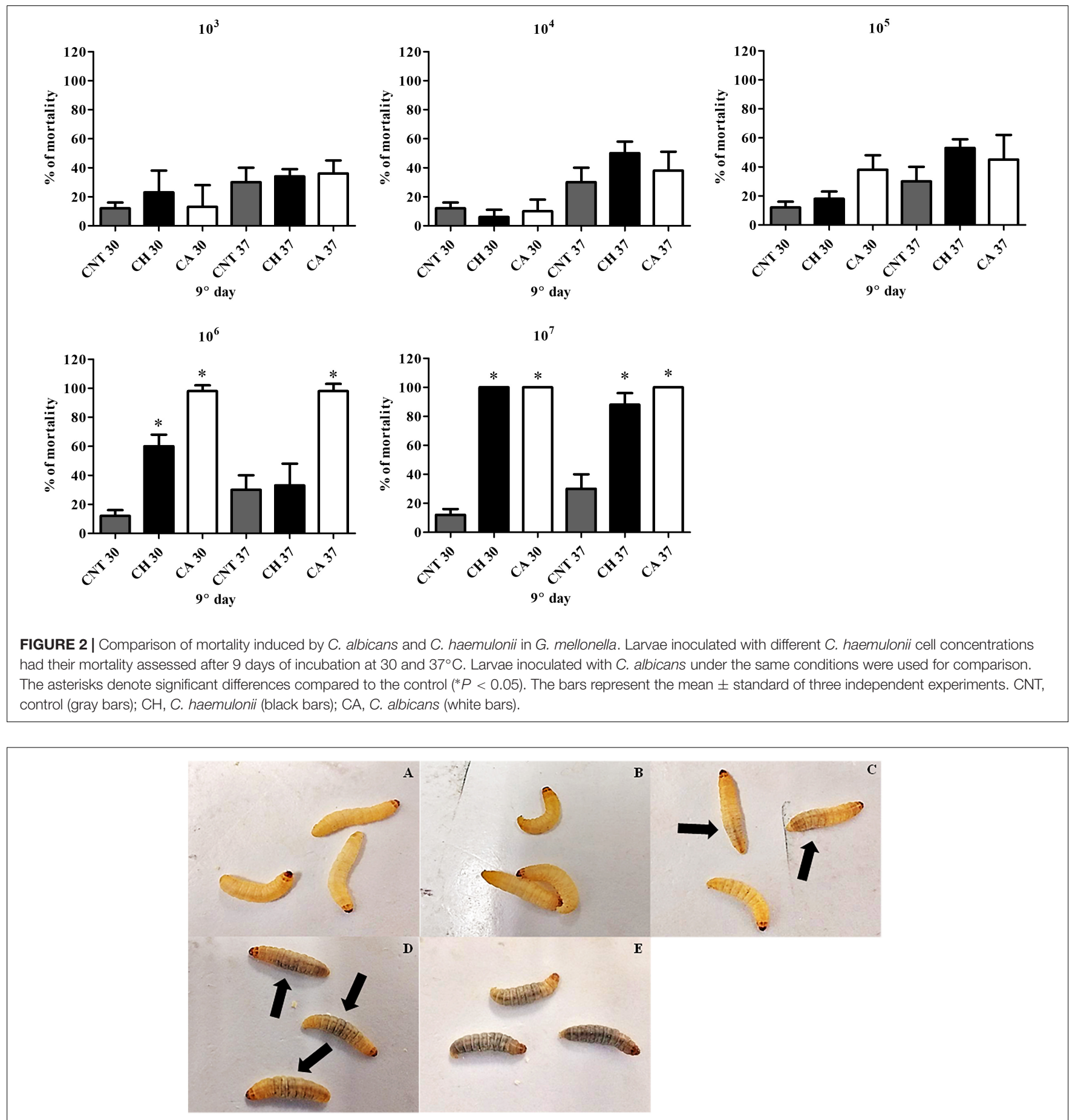

FIGURE 3 | Melanization process in G. mellonella infected with C. haemulonii. Larvae infected with different C. haemulonii inoculums ((A) $10^{3}$, (B) $10^{4}$, (C) $10^{5}$, (D) $10^{6}$, and (E) $10^{3}$ cells/larvae) were incubated for $1 \mathrm{~h}$ at $30^{\circ} \mathrm{C}$ and photographed. The arrows indicate melanized areas observable in the images.

but a significant increase was observed from 24 to $48 \mathrm{~h}$ of incubation $(P=0.04)$ (Figure 4). It remained stable in all analysis points in animals infected with the initial inoculums of $10^{4}$ and $10^{5}$ cells/larvae, indicating that the infection was kept under control by the larvae immune system. Increased infection progression and fungal burden was detected in an inoculum-dependent manner. Infecting animals with $10^{6}$ cells resulted in fungal burden progression from $6 \mathrm{~h}$ to $24 \mathrm{~h}(P=0.01)$ and from 24 to $48 \mathrm{~h}(P=0.003)$. Such increases were even more pronounced with the $10^{7}$ inoculum, with significant progression from 6 to $24 \mathrm{~h}(P=0.002)$ and from 24 to $48 \mathrm{~h}(P=0.001)$. 


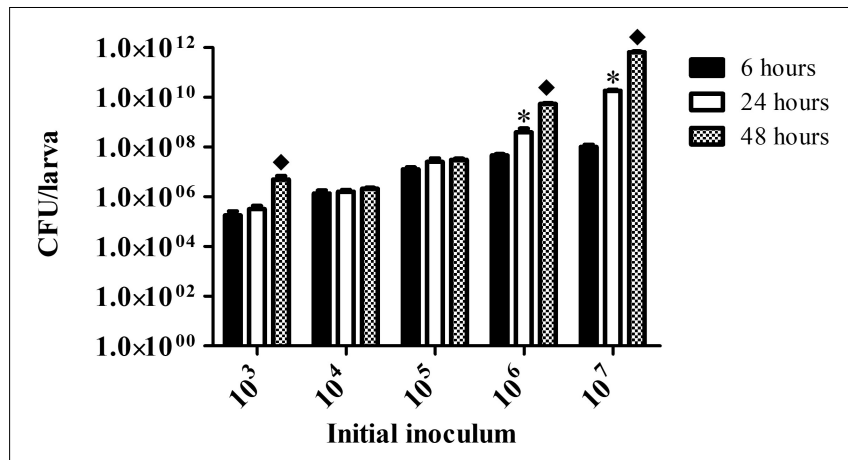

FIGURE 4 | Fungal burden in infected G. mellonella. Larvae infected with different $C$. haemulonii inoculum sizes were incubated at $30^{\circ} \mathrm{C}$ for up to $48 \mathrm{~h}$ At 6, 24, and $48 \mathrm{~h}$ incubation points, 3 random larvae were collected, sliced with a scalpel and macerated. The extract was then diluted and plated into agar sabouraud plates containing chloramphenicol. Plates were incubated for $48 \mathrm{~h}$ and the resulting number of colonies were counted. The asterisks denote significant differences between the 6 and $24 \mathrm{~h}$ point $\left({ }^{*} P<0.05\right)$. The diamond symbol denotes significant differences between the 24 and $48 \mathrm{~h}$ point $(\quad P<0.05)$. The bars represent the mean \pm standard of three independent experiments.

\section{Immune Modulation Induced by C. haemulonii Infection}

Hemocyte count for larvae infected with C. haemulonii indicated the presence of an inoculum-dependent immune response (Figure 5). No alterations in animals exposed to $10^{3}$ cells/larva were detected during the whole analysis. The highest immune response was observed with the $10^{4}$ inoculum, which significantly increased hemocyte density by $132.13 \%(6 \mathrm{~h}), 91.88 \%(24 \mathrm{~h})$, and $72.26 \%(48 \mathrm{~h})$ when compared with the PBS-inoculated control. The $10^{5}$ inoculum resulted in increased levels of hemocytes during the first $48 \mathrm{~h}$, while the $10^{6}$ and $10^{7}$ inoculums increased density after $6 \mathrm{~h}$, followed by a significant drop as time progressed. Due to high mortality rates, it was not possible to estimate hemocytes density on larvae infected with $10^{7}$ cells after $48 \mathrm{~h}$.

\section{Metal-Chelate Toxicity Evaluation Using G. mellonella Larvae}

After $72 \mathrm{~h}$ of exposure to the chelates, a dose-dependent toxicity to G. mellonella was detected. All animals tolerated doses of 2, 4, and $10 \mu \mathrm{g} / \mathrm{larvae}$ (Table 4), with no mortality observed. Similarly, chelates $4,6,7,8,10$, and 11 , at the concentration of $15 \mu \mathrm{g} / \mathrm{larvae}$, induced no mortality, while the remaining chelates resulted in $10 \%$ (9), $13.33 \%(5), 35 \%(3), 40 \%(2)$, and $60 \%$ (1) mortality. Increasing the chelate concentration to $30 \mu \mathrm{g} /$ larvae resulted in mortality rates ranging between 80 and $100 \%$, except for chelates 7 (30\%), 8 (13.33\%), 10 (33.33\%), and $11(20 \%)$.

\section{Immunomodulation Induced by the Chelates}

Control larvae (not exposed to any chelate) had a median hemocyte density of $75.8 \times 10^{6}$ cells $/ \mathrm{mL}$ (Figure 6). At an administered chelate concentration of $15 \mu \mathrm{g} / \mathrm{larva}$, animals

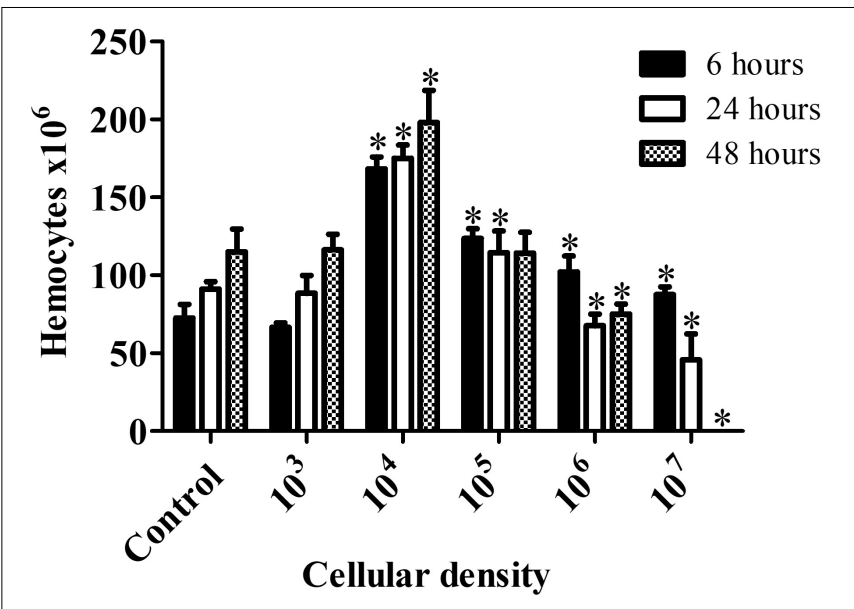

FIGURE 5 | Galleria mellonella immumodulation induced by C. haemulonii infection. Larvae were inoculated with different $C$. haemulonii inoculum sizes and incubated at $30^{\circ} \mathrm{C}$. Hemocytes were extracted and counted using a Neubauer chamber after 6,24 , and $48 \mathrm{~h}$ of incubation. The asterisks denote significant differences compared to the control $\left({ }^{*} P<0.05\right)$. The bars represent the mean \pm standard of three independent experiments.

exposed to chelates $3\left(101.2 \times 10^{6} / \mathrm{mL}\right), 5\left(90 \times 10^{6} / \mathrm{mL}\right), 7$ $\left(138 \times 10^{6} / \mathrm{mL}\right)$, and $8\left(149 \times 10^{6} / \mathrm{mL}\right)$ had significantly elevated hemocyte density. No significant differences were detected with chelates 2 and 11. Doubling the concentration to $30 \mu \mathrm{g} / \mathrm{larva}$ resulted in a reduction in hemocytes for chelates $3\left(15 \times 10^{6} / \mathrm{mL}\right)$ and $11\left(19.6 \times 10^{6} / \mathrm{mL}\right)$ and an increase with chelate 8 $\left(103 \times 10^{6} / \mathrm{mL}\right)$. Chelates 2,7 , and 10 did not induce significant alterations, whilst chelates $4,5,6$, and 9 , at $30 \mu \mathrm{g} /$ larva, negated all hemocytes. There was a complete absence of hemocytes when chelate 1 was used at both concentrations. The toxicity profiles of the chelates could be partially responsible for the hemocyte density alterations. Chelates used at $30 \mu \mathrm{g} /$ larva that induced $0 \%$ mortality (7 and 8) induced higher hemocyte density or did not affect it (11), while the more toxic chelates $(9,6,10$, and 4$)$ led to a significant reduction in hemocyte production.

\section{Metal-Chelate Effect on the Expression of Antimicrobial Peptides in G. mellonella}

The expression of the immune related peptide genes transferrin, IMPI, galiomicin, and gallerimycin in G. mellonella exposed to the metal-chelates was normalized against the $57 e$ reference gene (Figure 7). Transferrin and IMPI expression was significantly affected by the manganese(II) chelates 4, 5, 6 , and 8 and silver(I) chelates 9, 10, and $11(P<0.05)$. Galiomicin expression was increased by the silver(I) chelate 11, while gallerimycin expression was increased by the manganese(II) chelates 4 and $6(P<0.05)$. It is noteworthy that, besides affecting IMPI and transferrin expression, the manganese(II) chelates 5 and 8 are capable of increasing hemocyte density in G. mellonella, as previously described. 
TABLE 4 | Chelate toxicity toward G. mellonella.

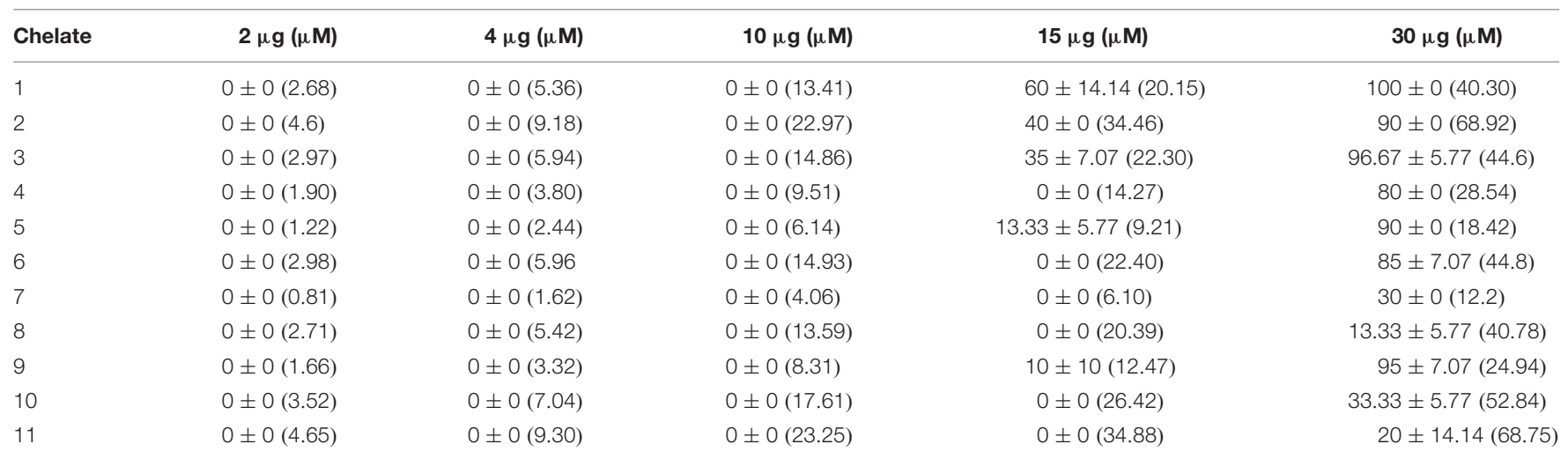

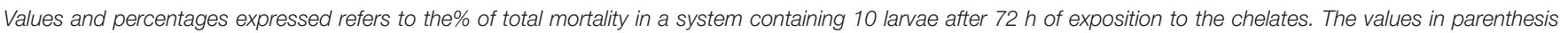
represents the chelate concentration in micromolar/larvae.

\section{Treatment Effect Over Fungal Burden in Infected Larvae of G. mellonella}

Candida haemulonii-infected G. mellonella were treated with the chelates in different concentrations $1 \mathrm{~h}$ post-infection. Analysis, after $24 \mathrm{~h}$ of treatment (Figure 8), indicates that chelates 3 and 8 significantly reduced the number of yeast cells present in the infected larvae at all of the chelate concentrations used. Chelate 5 reduced fungal burden at all concentrations except $0.625 \mu \mathrm{g} / \mathrm{larva}$, while chelates 4 and 7 reduced fungal burden at the two lowest test concentrations. An increase in the fungal burden was observed with chelates 4 and 11 at the highest concentration, with chelate 6 at 5 and $2.5 \mu \mathrm{g} / \mathrm{larva}$ and with chelate 2 across all administered concentrations. No significant differences were observed with the other chelates. Analysis at the $48 \mathrm{~h}$ post-treatment time revealed that only chelates 7 and 8 retained the ability to inhibit the fungal proliferation observed at

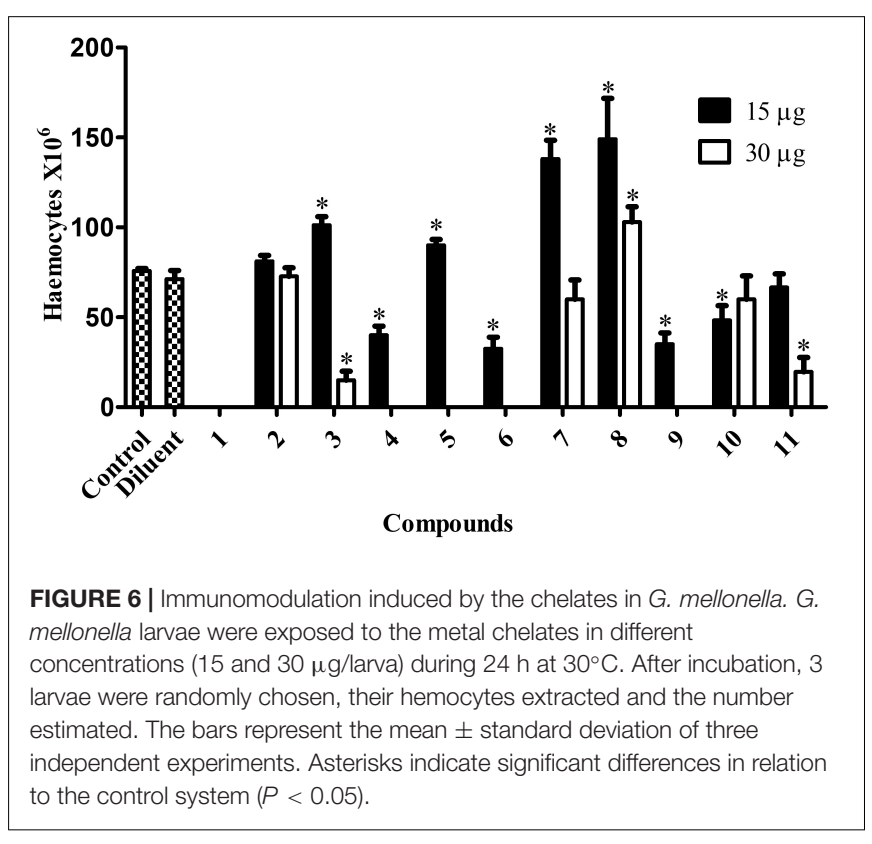

$24 \mathrm{~h}$ post-infection (Figure 9). All of the other chelates increased fungal burden or did not affect the number of fungal cells retrieved, except for compound 9.

\section{Pre-treatment Effect Over C. haemulonii Virulence}

Candida haemulonii cells were exposed to sub-inhibitory concentrations of the chelates $\left(1 / 2 \times \mathrm{IC}_{50}\right.$ and $\left.1 / 4 \times \mathrm{IC}_{50}\right)$ for $24 \mathrm{~h}$ before inoculation of $\mathrm{G}$. mellonella with these fungal cells. The analysis, $24 \mathrm{~h}$ post-infection, revealed that non-treated fungal cells caused $100 \%$ larvae mortality, while some of the chelates were capable of affecting the fungal virulence (Table 5). For C. haemulonii pre-treated with $1 / 2 \times \mathrm{IC}_{50}$, the manganese(II) chelates 2, 3, 5, and 6 and silver(I) chelate 11 were the most effective, reducing mortality rates by $55-100 \%$. Lowering the concentration of pre-administered chelates to $1 / 4 \times \mathrm{IC}_{50}$ resulted in no alterations in virulence with chelates 1 and 7 while the other chelates reduced mortality by $10-55 \%$. After $48 \mathrm{~h}$ of infection by the pre-treated $C$. haemulonii cells, larvae mortality rates were high (75-100\%) for all chelates except 3 and 5 (90\% reduction in mortality with $1 / 2 \times \mathrm{IC}_{50}$ ).

\section{DISCUSSION}

The emergence of new opportunistic fungal pathogens that are resistant to antifungal drugs is a major concern, and the WHO established a Global Antimicrobial Resistance Surveillance System (GLASS) to drive regional, national and global actions against antimicrobial resistance in the future (World Health Organization, 2019). There are many new antimicrobial resistant species emerging worldwide which include Candida, and among them is C. haemulonii, which possesses a reduced susceptibility profile to the available antifungal drugs (Ramos et al., 2015; Sanguinetti et al., 2015). New antifungal compounds are urgently required in order to circumvent this resistance profile. We have previously demonstrated the antifungal activity of copper(II), manganese(II), and silver(I) complexes containing phen-type ligands against the C. haemulonii complex (Gandra et al., 2017). Based on our previous results we selected one copper (1), seven 

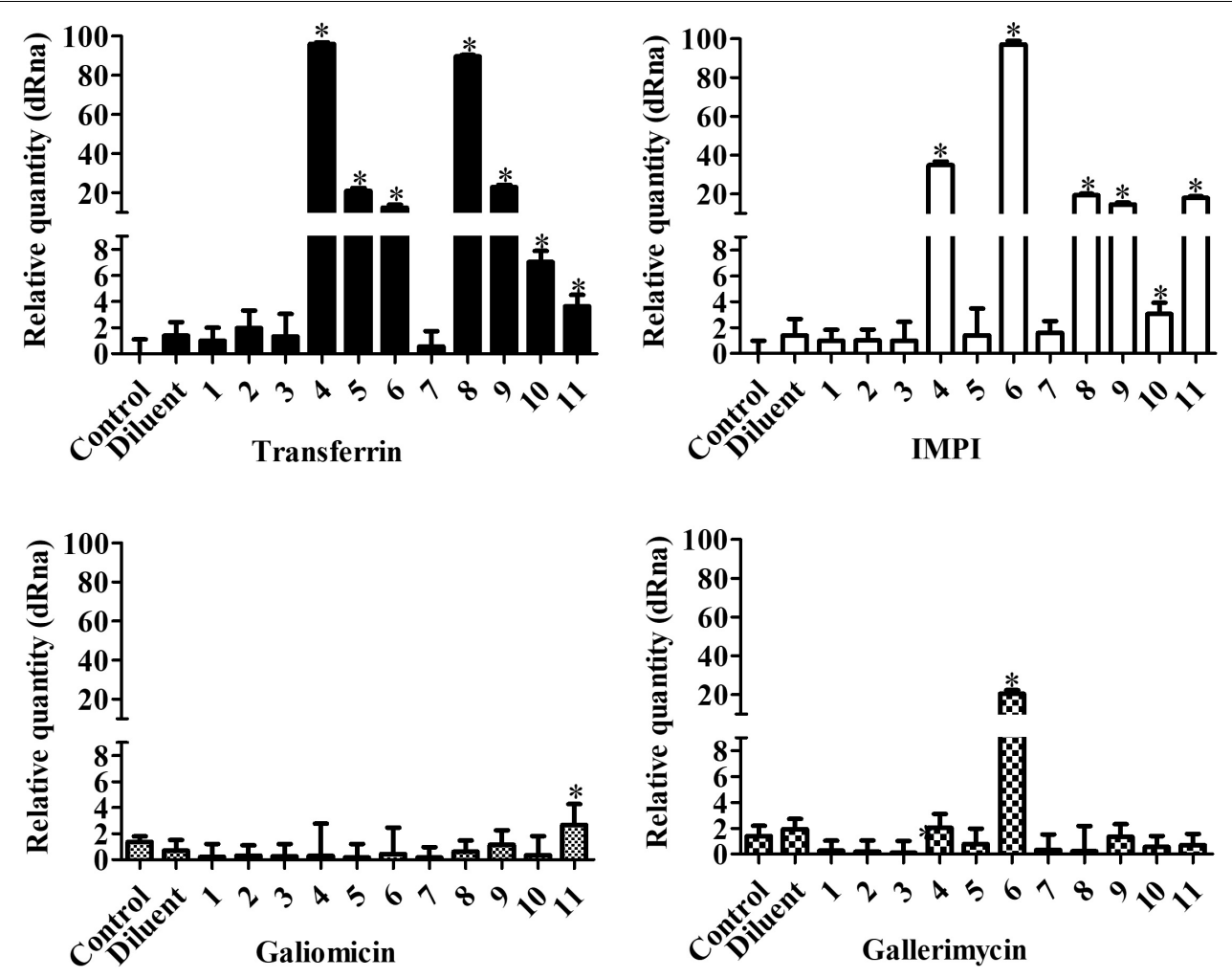

FIGURE 7 | Effect of chelates on antimicrobial peptide expression in G. mellonella. Larvae were inoculated with $10 \mu \mathrm{g} /$ larva of the chelates and incubated for $24 \mathrm{~h}$ at $30^{\circ} \mathrm{C}$. After that, total RNA was extracted and RT-PCR performed. The genes transferrin, IMPI, galiomycin, and gallerimycin were analyzed and PCR products were normalized against the housekeeping gene, S7e. The bars represent the mean \pm standard deviation of three independent experiments. Asterisks indicate significant differences in relation to the control system $(P<0.05)$.

manganese (2-8), and three silver chelates (9-11) for further analysis using the insect larvae, G. mellonella, a model widely employed as a first choice for preliminary in vivo antimicrobial drug testing. Initial analysis revealed that the chelates have a fungicidal activity at higher concentrations and fungistatic activity in lower doses, a profile previously described for antibiotic drugs such as fluconazole, voriconazol and caspofungin (Meletiadis et al., 2007; Venisse et al., 2008; Domán et al., 2015; Lee and Lee, 2018). A recent meta-analysis suggests that fungicidal drugs might have an advantage regarding early therapeutic success (Kumar et al., 2018), making the fungicidal properties of the chelates a possible advantageous property.

The current virulence studies using G. mellonella revealed that fungal inoculum size was directly associated with the infection outcome and that C. haemulonii was less virulent than C. albicans, with 10-times more $C$. haemulonii cells required to obtain similar mortality rates. This finding corroborates previous data demonstrating a higher $C$. albicans virulence to $G$. mellonella in comparison with other Candida species (Cotter et al., 2000; Bergin et al., 2003; Scorzoni et al., 2013). Incubation temperature also directly impacted on Candida virulence and mortality induced by the infection. C. albicans was found to be more virulent at the higher temperature of $37^{\circ} \mathrm{C}$ (compared to $30^{\circ} \mathrm{C}$ ), a feature previously known for this species and other pathogenic fungi such as Aspergillus terreus, Cryptococcus neoformans, and
Cryptococcus gattii (Scorzoni et al., 2013; Maurer et al., 2015; Rossi et al., 2016). However, C. haemulonii had the opposite temperature profile, with a higher mortality rate in larvae incubated at $30^{\circ} \mathrm{C}$. This trend may be explained by examining the $C$. haemulonii isolation history, first from the gut of the fish Haemulon sciurus, and subsequently from dolphin skin and from seawater (Van Uden and Kolipinski, 1962; Gargeya et al., 1991; Khan et al., 2007). Curiously, the optimum temperature of the H. sciurus ranges between 25.5 and $28^{\circ} \mathrm{C}$, in a median of $27.3^{\circ} \mathrm{C}$ (Kaschner et al., 2016). Such information could explain why, although C. haemulonii is capable of causing infections at $37^{\circ} \mathrm{C}$, it has a higher virulence at $30^{\circ} \mathrm{C}$, which could, in part, be the reason for the low incidence of this species as etiologic agents in human infections.

An inoculum-dependent fungal burden, hemocyte density and melanization processes was detected, and these aspects seem to be interrelated. For instance, while larvae infection with $10^{4}$ and $10^{5}$ cells resulted in a stable fungal burden over time, in larvae infected with $10^{3}$ cells/larva proliferation occurred. Such a phenomenon might be associated with the fact that the $10^{3}$ inoculum induced no increase in hemocytes, thus allowing the fungal cells to proliferate. Contrarily, the $10^{4}$ and $10^{5}$ inoculums resulted in increased hemocyte density and a small melanization process $\left(10^{5}\right)$, which might have kept fungal proliferation under control, since such an increase in circulating hemocytes is 

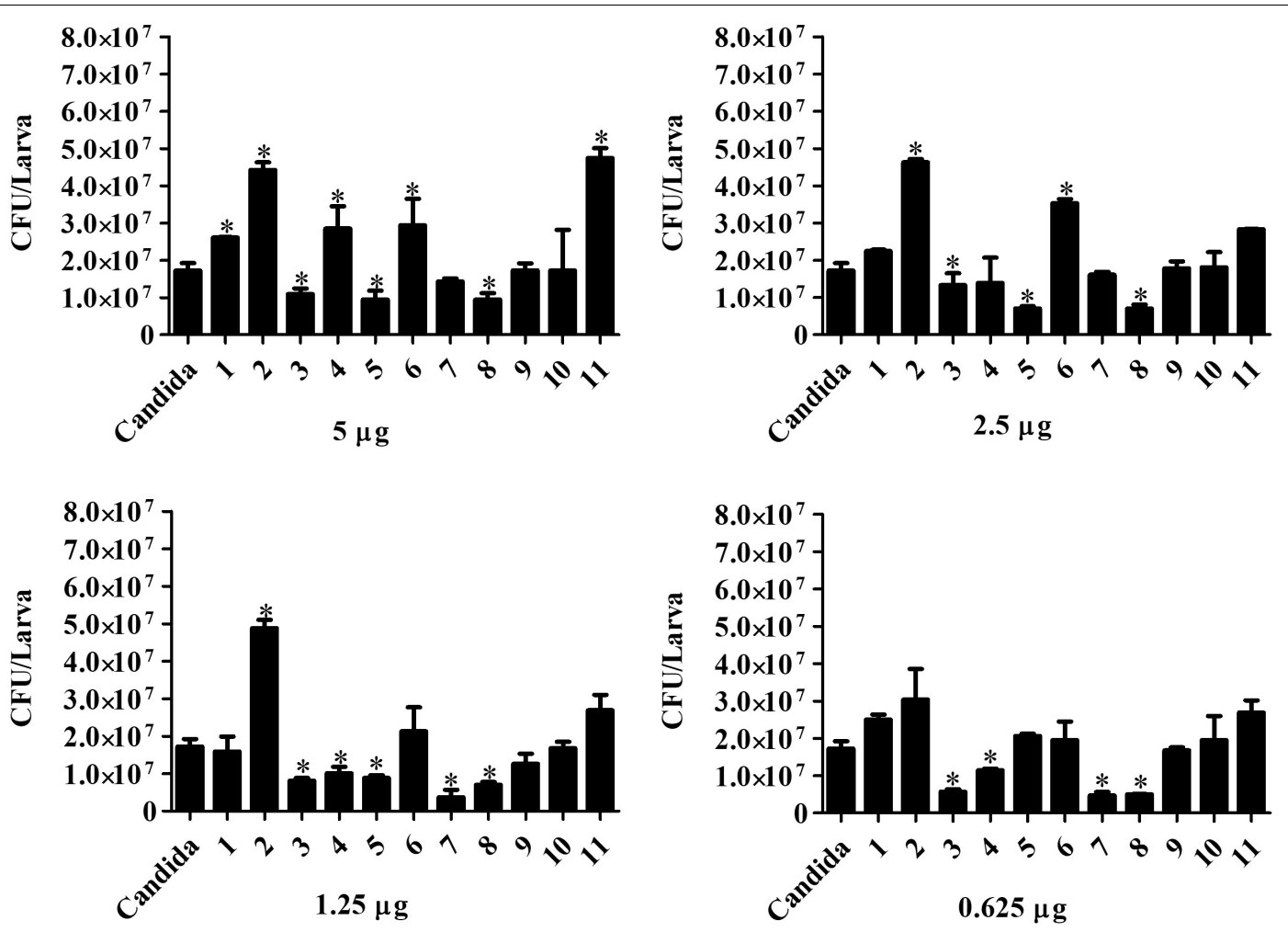

FIGURE 8 | Effect of chelate treatment ( $24 \mathrm{~h}$ ) on fungal burden in infected larvae of G. mellonella. Larvae infected with $5 \times 10^{5}$ cells/larva of $\mathrm{C}$. haemulonii were treated with the chelates $1 \mathrm{~h}$ post-infection. The larvae extract was plated into agar sabouraud containing chloramphenicol and the resulting number of colonies counted. Asterisks indicate significant differences in relation to the control system $(P<0.05)$.

known to protect $G$. mellonella against fungal pathogens (Mowlds et al., 2008). Severe melanization was observed with the $10^{6}$ and $10^{7}$ inoculum, which coincided with reduced hemocyte density. This could be explained by data that suggest that, although the G. mellonella immune response is primarily through phagocytosis, when faced with a large number of invading microorganisms the nodulation/melanization process is mainly used by the larvae (Dunphy et al., 1986; Wu et al., 2016). Such an inoculum-dependent strategy adopted by the larvae observed in our assays was previously described in studies estimating hemocyte density in larvae inoculated with Aspergillus fumigatus, C. albicans, and Saccharomyces cerevisiae and in melanization studies using C. albicans and C. krusei (Bergin et al., 2006; Mowlds et al., 2010; Fallon et al., 2011a; Scorzoni et al., 2013).

All of the metal-chelates were well tolerated by G. mellonella in concentrations of up to $500 \mathrm{mg} / \mathrm{L}(10 \mu \mathrm{g} / \mathrm{larva})$, but at $750 \mathrm{mg} / \mathrm{L}(15 \mu \mathrm{g} /$ larva $)$ some mortality occurred, which increased upon raising the concentration of administered chelate. Regarding the type of metal ion contained in the chelate, the solitary copper(II) complex (chelate 1) had a high toxicity profile, while the manganese(II) chelate (8) induced the lowest mortality rate. In this context, our previous study using A549 cells revealed that copper(II) chelates had very low selectivity indexes, while manganese(II) chelates demonstrated very high selectivity indexes (Gandra et al., 2017). This demonstrates that chelates containing copper(II) ions are more toxic than their manganese(II) and silver(I) counterparts toward both mammalian cells and G. mellonella. It is important to mention that the MIC values previously established with the chelates for all species of the C. haemulonii complex ranged between 0.26 and $5.96 \mathrm{mg} / \mathrm{L}$ (Gandra et al., 2017), which was much lower than the highest non-toxic concentration of all chelates $(500 \mathrm{mg} / \mathrm{L})$ observed in the present study.

The chelates, particularly the manganese(II) species (8), also demonstrated immunomodulation properties, affecting the hemocyte density and the gene expression of antimicrobial peptides (AMPs), especially transferrin and IMPI, which are key components of the larvae immune system and responsible for eliminating pathogens that have evaded the cellular response (Bergin et al., 2006). Such characteristics could be useful for a possible novel antifungal chelate, since previous studies have demonstrated that antifungal drugs, besides inhibiting proliferation and killing fungal cells, possess immunomodulatory properties that confer an additional combat mechanism against such antimicrobial resistant infections (Mesa-Arango et al., 2012). For instance, amphotericin B is capable of inducing different cell lines to produce nitric oxide (NO), prostaglandins and reactive oxygen intermediates, besides several cytokines and chemokines. Furthermore, amphotericin B, fluconazole, voriconazole, micafungin, and caspofungin are all capable of increasing the antifungal activity of different immune cells such as macrophages, polymorphonuclear leukocytes (PMN) and 

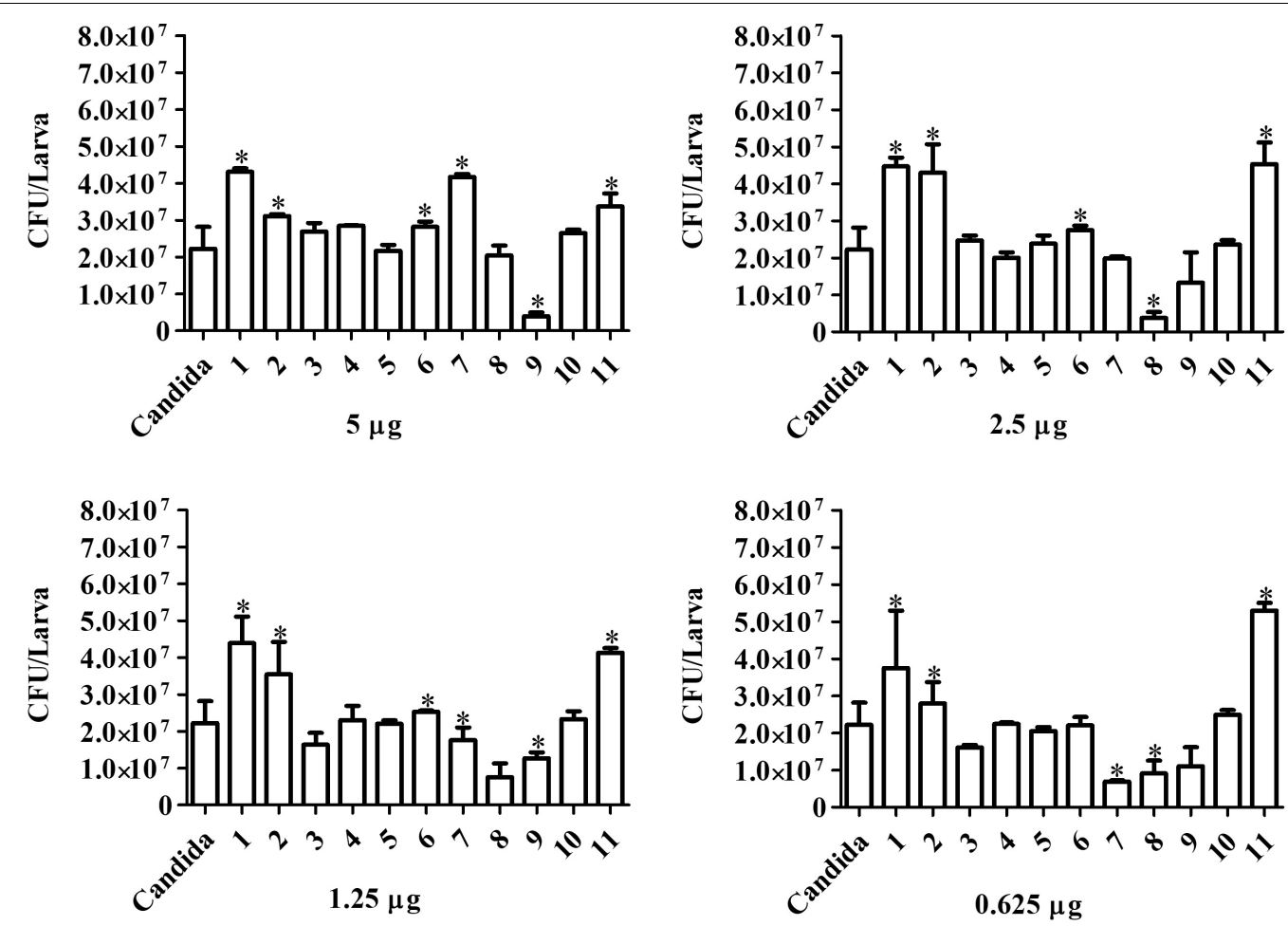

FIGURE 9 | Forty-eight hours treatment effect over fungal burden in infected larvae of G. mellonella. Larvae infected with $5 \times 10^{5}$ cells/larvae of C. haemulonii and treated with different chelates concentration $1 \mathrm{~h}$ post-infection were macerated, and the extract diluted and plated into agar sabouraud plates containing chloramphenicol. Asterisks indicate significant differences in relation to the control system $(P<0.05)$.

monocytes (Tohyama et al., 1996; Cenci et al., 1997; Chiller et al., 2001; Roilides et al., 2002; Choi et al., 2004; Ben-Ami et al., 2008; Mesa-Arango et al., 2012; Scorzoni et al., 2013; Fuchs et al., 2016). A similar increase in hemocyte density and AMPs expression in G. mellonella is induced by the antifungal drug caspofungin, which confers higher resistance to subsequent C. albicans infections (Kelly and Kavanagh, 2011). Since such immunomodulatory effects are another possible mechanism that aids the host in fighting an infection and are induced by different antifungal drugs, these immunomodulatory properties demonstrated by the chelates are an interesting trait.

Fungal burden was reduced by chelates $3,4,5,7$, and 8 with at least one of the concentrations used. Interestingly, all of these chelates, except the manganese(II) species (4), also induced an increase in hemocyte density in the larvae. In a previous study with larvae infected with $C$. albicans and treated with fluconazole and fluconazole associated with tetracycline-derived drugs, a similar reduction in fungal burden was reported ( $\mathrm{Gu}$ et al., 2017). However, it is noteworthy that the drug concentrations used to achieve such an effect were much higher than the chelate concentrations used in the present study. The same study reported a gradual increase in the number of CFUs obtained from infected animals over time, indicating a limited drug activity, which a similar feature observed in the current study. Surprisingly, chelate 8 retained most of its anti-proliferation capacity, with similar numbers of CFUs obtained after 24 and $48 \mathrm{~h}$ of treatment. This result is important as it demonstrates that the chelates are capable of a direct in vivo effect and are not acting only through a secondary effect, as the immune response induced in the previous assays.

TABLE 5 | Impact on virulence of Candida haemulonii toward G. mellonella following pre-exposure of the fungal cells to sub-inhibitory concentrations of the chelates.

\begin{tabular}{lcccc}
\hline \multirow{2}{*}{ Chelate } & \multicolumn{3}{c}{ Time of infection (hours) } \\
\cline { 2 - 5 } & \multicolumn{2}{c}{$\mathbf{2 4}$} & $\mathbf{4 8}$ \\
\hline Control & \multicolumn{2}{c}{$0 \pm 0$} & $0 \pm 0$ \\
Candida haemulonii & \multicolumn{2}{c}{$85 \pm 7.07$} & $100 \pm 0$ \\
\hline Concentration & $\mathbf{1 / 2} \mathbf{I C}_{\mathbf{5 0}}$ & $\mathbf{1 / 4} \mathbf{I C}_{\mathbf{5 0}}$ & $\mathbf{1 / 2} \mathbf{I C}_{\mathbf{5 0}}$ & $\mathbf{1 / 4} \mathbf{I C}_{\mathbf{5 0}}$ \\
\hline 1 & $85 \pm 7.07$ & $100 \pm 0$ & $100 \pm 0$ & $100 \pm 0$ \\
2 & $45 \pm 7.07$ & $55 \pm 7.07$ & $80 \pm 14.14$ & $100 \pm 0$ \\
3 & $5 \pm 7.07$ & $75 \pm 21.21$ & $10 \pm 0$ & $100 \pm 0$ \\
4 & $85 \pm 7.07$ & $70 \pm 0$ & $100 \pm 0$ & $100 \pm 0$ \\
5 & $0 \pm 0$ & $45 \pm 7.07$ & $10 \pm 14.14$ & $100 \pm 0$ \\
6 & $15 \pm 7.07$ & $60 \pm 0$ & $90 \pm 0$ & $100 \pm 0$ \\
7 & $65 \pm 7.07$ & $100 \pm 0$ & $100 \pm 0$ & $100 \pm 0$ \\
8 & $50 \pm 0$ & $60 \pm 14.14$ & $90 \pm 14.14$ & $90 \pm 0$ \\
9 & $65 \pm 7.07$ & $90 \pm 0$ & $100 \pm 0$ & $100 \pm 0$ \\
10 & $70 \pm 0$ & $85 \pm 7.07$ & $90 \pm 0$ & $100 \pm 0$ \\
11 & $15 \pm 7.07$ & $90 \pm$ & $75 \pm 7.07$ & $100 \pm 0$
\end{tabular}


The increase in fungal burden observed with some chelates might be due to a reduction in hemocyte density or to impaired hemocyte activity when the density was not affected. With the latter scenario, our hypothesis is that the chelates might be affecting the production of reactive oxygen species (ROS) by the NADPH oxidase complex, which is essential for the larvae immune system and hemocytes to fight invading agents (Browne et al., 2013). To exemplify, it is known that fumagilin, a toxin produced by A. fumigatus, reduces neutrophil capacity of phagocyting and killing microorganisms due to reduced formation of the NADPH oxidase complex (Fallon et al., 2010). It has also been described that, although no reduction in G. mellonella or hemocyte viability was observed, fumagilin induces a reduction in hemocytes oxygen uptake, which indicates reduced ROS production since this depends on a sufficient oxygen supply besides a functioning NADPH oxidase complex. Additionally, fumagilin also reduces the hemocyte capacity of phagocyting opsonized conidia of A. fumigatus and opsonized C. albicans cells (Fallon et al., 2010, 2011b). Neutrophils and hemocytes possesses similarities regarding oxidative burst, presence of homolog proteins $\mathrm{p} 40^{\text {phox }}, \mathrm{p} 47^{\text {phox }}$, p67 $67^{\text {phox }}$ e gp91 phox and similar microorganism elimination through the NADPH oxidase complex activity. Such information could indicate that the reduction in the hemocyte immunologic capacity occurs by a similar mechanism observed in neutrophils, the non-functionality of the NADPH complex (Fallon et al., 2011b). Knowing that chelates containing phen and related ligands are capable of uncoupling mitochondrial respiration (McCann et al., 2004), our hypothesis is that some of the present chelates are affecting the formation or activity of the NADPH oxidase complex, and interfering with the ROS formation capacity of hemocytes, reducing its phagocytosis and killing capacity.

Finally, a dramatic reduction in larvae mortality was observed when $C$. haemulonii cells were exposed to chelates 2, 3, 5, 6, 8, and 11 prior to infection of G. mellonella larvae. Such an outcome is known as the post-antifungal effect (PAFE), which is described as an inhibition of fungal proliferation after a limited exposure to an antifungal agent (Minguez et al., 1994). Such an attenuated virulence of C. albicans, Candida Tropicalis, and Candida kefyr was previously reported for these fungal cells upon exposure to sub-inhibitory concentrations of amphotericin $\mathrm{B}$, fluconazole, ketoconazole, and 5-flucitosine, which affected aspects such as growth rate, susceptibility to PMN leukocytes and adhesion capacity to buccal epithelial cells (Abu-El Teen et al., 1989; Minguez et al., 1994, 1997). The capacity of the metal-chelates to affect $C$. haemulonii virulence in a similar way to classical antifungal drugs reinforces the possible potential of using such compounds as antifungal agents.

\section{REFERENCES}

Abu-El Teen, K., Ghannum, M., and Stretton, R. J. (1989). Effects of sub-inhibitory concentrations of antifungal agents on adherence of Candida spp. to buccal epithelial cells in vitro. Mycoses 32, 551-562. doi: 10.1111/j.1439-0507.1989. tb02180.x
In summary, our data indicates that manganese(II) and silver(I) chelates containing the phen ligand have potent antiC. haemulonii activity and are reasonably non-toxic toward G. mellonella. Variations in toxicity levels and on the immune response of larvae exposed to the chelates indicates that chemical structural differences, even minimal ones, directly impacts over how the chelates affect the fungal cells and the host, G. mellonella. The manganese(II) chelate, 8 , demonstrated very interesting characteristics, possessing very good antifungal capacity, low toxicity, a capacity to induce an immune response and to reduce the fungal burden on infected animals and also an ability to affect $C$. haemulonii virulence. More research is needed in order to better understand the mechanisms of action of the chelates and to allow for the development of new compounds that are more active and less toxic and which could become alternative therapeutic agents for treating multi-resistant Candida species. We believe that the present study offers important insights for the future treatment of antimicrobial resistant pathogens worldwide.

\section{DATA AVAILABILITY STATEMENT}

All datasets generated for this study are included in the article/supplementary material.

\section{AUTHOR CONTRIBUTIONS}

RG, LV, KK, AS, OH, and MD conceived and designed the study. RG, PM, and MF performed the experiments. All authors analyzed the data. $\mathrm{MM}, \mathrm{MB}, \mathrm{AS}, \mathrm{OH}$, and $\mathrm{MD}$ contributed reagents, materials, and/or analysis tools. RG, AS, $\mathrm{MM}, \mathrm{OH}$, and MD wrote and revised the manuscript. All authors contributed to the research and approved the final version of the manuscript. All authors agreed to be accountable for all aspects of the work.

\section{FUNDING}

This study was supported by grants and fellowships from the Government of Ireland International Education Scholarships Programme, the Research Brazil Ireland (RBI) mobility initiative funded under the Science Foundation Ireland (SFI) International Strategic Cooperation Award (ISCA) Programme and the Brazilian agencies Conselho Nacional de Desenvolvimento Científico e Tecnológico (CNPq), Fundação de Amparo à Pesquisa do Estado do Rio de Janeiro (FAPERJ), and Coordenacão de Aperfeiçoamento de Pessoal de Nível Superior (CAPES - Finance Code 001).

Arendrup, M. C., and Patterson, T. F. (2017). Multidrug-resistant Candida: epidemiology, molecular mechanisms, and treatment. J. Infect. Dis. 216(Suppl. 3), S445-S451. doi: 10.1093/infdis/ji x131

Barnoy, S., Gancz, H., Zhu, Y., Honnold, C. L., Zurawski, D. V., and Venkatesan, M. M. (2017). The galleria mellonella larvae as an in vivo model for evaluation 
of shigella virulence. Gut Microbes 8, 335-350. doi: 10.1080/19490976.2017. 1293225

Ben-Ami, R., Lewis, R. E., and Kontoyiannis, D. P. (2008). Immunocompromised hosts: immunopharmacology of modern antifungals. Clin. Infect. Dis. 47, 226235. doi: $10.1086 / 589290$

Benedict, K., Richardson, M., Vallabhaneni, S., Jackson, B. R., and Chiller, T. (2017). Emerging issues, challenges, and changing epidemiology of fungal disease outbreaks. Lancet Infect. Dis. 17, e403-e411. doi: 10.1016/S1473-3099(17) 30443-30447

Bergin, D., Brennan, M., and Kavanagh, K. (2003). Fluctuations in haemocyte density and microbial load may be used as indicators of fungal pathogenicity in larvae of Galleria mellonella. Microbes Infect. 5, 1389-1395. doi: 10.1016/j. micinf.2003.09.019

Bergin, D., Murphy, L., Keenan, J., Clynes, M., and Kavanagh, K. (2006). Preexposure to yeast protects larvae of Galleria mellonella from a subsequent lethal infection by Candida albicans and is mediated by the increased expression of antimicrobial peptides. Microbes Infect. 8, 2105-2112. doi: 10.1016/j.micinf. 2006.03.005

Browne, N., Heelan, M., and Kavanagh, K. (2013). An analysis of the structural and functional similarities of insect haemocytes and mammalian phagocytes. Virulence 4, 597-603. doi: 10.4161/viru.25906

Casey, M. T., McCann, M., Devereux, M., Curran, M., Cardin, C., Convery, M., et al. (1994). Synthesis and structure of the Mn2 (II, II) complex salt [Mn2(oda)(phen)4(H2O)2] [Mn2(oda)2(phen)4] (odaH2= octanedioic acid): a catalyst for $\mathrm{H} 2 \mathrm{O} 2$ disproportionation. J. Chem. Soc. Chem. Commun. 22, 2643-2645. doi: 10.1039/C39940002643

Castelli, M. V., Butassi, E., Monteiro, M. C., Svetaz, L. A., Vicente, F., and Zacchino, S. A. (2014). Novel antifungal agents: a patent review (2011 - present). Expert Opin. Ther. Pat. 24, 323-328. doi: 10.1517/13543776.2014.876993

Cenci, E., Mencacci, A., Del Sero, G., Bistoni, F., and Romani, L. (1997). Induction of protective Th1 response to Candida albicans by antifungal therapy alone or in combination with an interleukin-4 antagonist. J. Infect. Dis. 176, 217-226. doi: $10.1086 / 514027$

Cendejas-Bueno, E., Kolecka, A., Alastruey-Izquierdo, A., Theelen, B., Groenewald, M., Kostrzewa, M., et al. (2012). Reclassification of the Candida haemulonii complex as Candida haemulonii (C. haemulonii group I), C. duobushaemulonii sp. nov. (C. haemulonii group II), and C. haemulonii var. vulnera var. nov.: three multiresistant human pathogenic yeasts. J. Clin. Microbiol. 50, 3641-3365. doi: 10.1128/JCM.02248-12

Chamilos, G., Lionakis, M. S., Lewis, R. E., and Kontoyiannis, D. P. (2007). Role of mini-host models in the study of medically important fungi. Lancet Infect. Dis. 7, 42-55. doi: 10.1016/s1473-3099(06)70686-7

Chiller, T., Farrokhshad, K., Brummer, E., and Stevens, D. A. (2001). The interaction of human monocytes, monocyte-derived macrophages and polymorphonuclear neutrophils with caspofungin (MK-0991), an echinocandin, for antifungal activity against Aspergillus fumigatus. Diagn. Microbiol. Infect. Dis. 39, 99-103. doi: 10.1016/s0732-8893(00)00 236-4

Choi, J. H., Brummer, E., and Stevens, D. A. (2004). Combined action of micafungin, a new echinocandin, and human phagocytes for antifungal activity against Aspergillus fumigatus. Microbes Infect. 6, 383-389. doi: 10.1016/j.micinf. 2003.12.010

CLSI, (2008). Reference Method for Broth Dilution Antifungal Susceptibility Testing of Yeasts: Approved Standard, 3rd Edn, M27-A3. Wayne, PA: Clinical and Laboratory Standards Institute.

Cotter, G., Doyle, S., and Kavanagh, K. (2000). Development of an insect model for the in vivo pathogenicity testing of yeasts. FEMS Immunol. Med. Microbiol. 27, 163-169. doi: 10.1111/j.1574-695X.2000.tb01427.x

Coyle, B., Kavanagh, K., McCann, M., Devereux, M., and Geraghty, M. (2003). Mode of anti-fungal activity of 1, 10-phenanthroline and its $\mathrm{Cu}$ (II), Mn (II) and $\mathrm{Ag}(\mathrm{I})$ complexes. Biometals 16, 321-329.

Creaven, B. S., Egan, D. A., Karcz, D., Kavanagh, K., McCann, M., Mahon, M., et al. (2007). Synthesis, characterization and antimicrobial activity of copper(II) and manganese(II) complexes of coumarin-6,7-dioxyacetic acid (cdoaH2) and 4-methylcoumarin-6,7-dioxyacetic acid (4-MecdoaH2): X-ray crystal structures of $[\mathrm{Cu}(\mathrm{cdoa})($ phen $) 2] .8 .8 \mathrm{H} 2 \mathrm{O}$ and $[\mathrm{Cu}(4-\mathrm{Mecdoa})(\mathrm{phen}) 2] .13 \mathrm{H} 2 \mathrm{O}$ (phen=1,10-phenanthroline). J. Inorg. Biochem. 101, 1108-1119. doi: 10.1016/ j.jinorgbio.2007.04.010
Desbois, A. P., and Coote, P. J. (2012). Utility of greater wax moth (Galleria mellonella) for evaluating the toxicity and efficacy of new antimicrobial agents. Adv. Appl. Microbiol. 78, 25-53. doi: 10.1016/B978-0-12-394805-2.00002-6

Devereux, M., McCann, M., Leon, V., Geraghty, M., McKee, V., and Wikaira, J. (2000). Synthesis and biological activity of manganese (II) complexes of phthalic and isophthalic acid: X-ray crystal structures of $[\mathrm{Mn}(\mathrm{ph})(\mathrm{Phen}) 2(\mathrm{H} 2 \mathrm{O})] .4 \mathrm{H} 2 \mathrm{O}, \quad[\mathrm{Mn}(\mathrm{Phen}) 2(\mathrm{H} 2 \mathrm{O}) 2] 2 \quad(\mathrm{Isoph}) 2$ (Phen) $14 \mathrm{H} 2 \mathrm{O}$ and $\{[\mathrm{Mn}(\mathrm{Isoph})(\mathrm{bipy}) 2] 4.2 .75 \mathrm{bipy}\} \mathrm{n}$ (phH2 = phthalic acid; Isoph = isophthalic acid; Phen = 1,10-phenanthroline; bipy = 2,2-bipyridine). Met. Based Drugs 7, 275-288. doi: 10.1155/mbd.2000.275

Domán, M., Kovács, R., Perlin, D. S., Kardos, G., Gesztelyi, R., Juhász, B., et al. (2015). Dose escalation studies with caspofungin against Candida glabrata. J. Med. Microbiol. 64(Pt 9), 998-1007. doi: 10.1099/jmm.0.000116

Dunphy, G. B., Morton, D. B., Andrew, K., and Chadwick, J. M. (1986). Pathogenicity of lipopolysaccharide mutants of Pseudomonas aeruginosa for larvae of Galleria mellonella: bacterial properties associated with virulence. J. Invertebr. Pathol. 47, 48-55. doi: 10.1016/0022-2011(86)90162-x

Fallon, J. P., Reeves, E. P., and Kavanagh, K. (2010). Inhibition of neutrophil function following exposure to the Aspergillus fumigatus toxin fumagillin. J. Med. Microbiol. 59, 625-633. doi: 10.1099/jmm.0.018192-0

Fallon, J. P., Reeves, E. P., and Kavanagh, K. (2011a). The Aspergillus fumigatus toxin fumagillin suppresses the immune response of Galleria mellonella larvae by inhibiting the action of haemocytes. Microbiology 157(Pt 5), 1481-1488. doi: $10.1099 / \mathrm{mic} .0 .043786-0$

Fallon, J. P., Troy, N., and Kavanagh, K. (2011b). Pre-exposure of Galleria mellonella larvae to different doses of Aspergillus fumigatus conidia causes differential activation of cellular and humoral immune responses. Virulence 2, 413-421. doi: 10.4161/viru.2.5.17811

Fuchs, B. B., Li, Y., Li, D., Johnston, T., Hendricks, G., Li, G., et al. (2016). Micafungin elicits an immunomodulatory effect in Galleria mellonella and mice. Mycopathologia 181, 17-25. doi: 10.1007/s11046-015-9940-z

Gandra, R. M., McCarron, P., Fernandes, M. F., Ramos, L. S., Mello, T. P., Aor, A. C., et al. (2017). Antifungal potential of copper(II), manganese(II) and silver(I) 1,10-phenanthroline chelates against multidrug-resistant fungal species forming the Candida haemulonii complex: impact on the planktonic and biofilm lifestyles. Front. Microbiol. 8:1257. doi: 10.3389/fmicb.2017.01257

Gargeya, I. B., Pruitt, W. R., Meyer, S. A., and Ahearn, D. G. (1991). Candida haemulonii from clinical specimens in USA. J. Med. Vet. Mycol. 29, 335-338.

Geraghty, M., Cronin, J. F., Devereux, M., and McCann, M. (2000). Synthesis and antimicrobial activity of copper (II) and manganese (II) $\alpha, \omega$-dicarboxylate complexes. Biometals 13, 1-8.

Gu, W., Yu, Q., Yu, C., and Sun, S. (2017). In vivo activity of fluconazole/tetracycline combinations in Galleria mellonella with resistant Candida albicans infection. J. Glob. Antimicrob. Resist. 13, 74-80. doi: 10.1016/j.jgar.2017.11.011

Hamdy, R. F., Zaoutis, T. E., and Seo, S. K. (2016). Antifungal stewardship considerations for adults and pediatrics. Virulence 8, 658-672. doi: 10.1080/ 21505594.2016.1226721

Kaschner, K., Kesner-Reyes, K., Garilao, C., Rius-Barile, J., Rees, T., and Froese, R. (2016). AquaMaps: Predicted Range Maps for Aquatic Species. World Wide Web electronic publication. Available online at: www.aquamaps.org (accessed March 27, 2019).

Kavanagh, K., and Sheehan, G. (2018). The use of Galleria mellonella larvae to identify novel antimicrobial agents against fungal species of medical interest. J. Fungi (Basel) 4:E113. doi: 10.3390/jof4030113

Kelly, J., and Kavanagh, K. (2011). Caspofungin primes the immune response of the larvae of Galleria mellonella and induces a non-specific antimicrobial response. J. Med. Microbiol. 60(Pt 2), 189-196. doi: 10.1099/jmm.0.025494-0

Khan, Z. U., Al-Sweih, N. A., Ahmad, S., Al-Kazemi, N., Khan, S., Joseph, L., et al. (2007). Outbreak of fungemia among neonates caused by Candida haemulonii resistant to amphotericin B, itraconazole and fluconazole. J. Clin. Microbiol. 45, 2025-2027. doi: $10.1128 / \mathrm{jcm} .00222-07$

Kim, M. N., Shin, J. H., Sung, H., Lee, K., Kim, E. C., Ryoo, N., et al. (2009). Candida haemulonii and closely related species at 5 university hospitals in Korea: identification, antifungal susceptibility, and clinical features. Clin. Infect. Dis. 48, e57-e61. doi: 10.1086/597108

Kullberg, B. J., and Arendrup, M. C. (2015). Invasive candidiasis. N. Engl. Med. 373, 1445-1456. doi: 10.1056/NEJMra1315399 
Kumar, A., Zarychanski, R., Pisipati, A., Kumar, A., Kethireddy, S., and Bow, E. J. (2018). Fungicidal versus fungistatic therapy of invasive Candida infection in non-neutropenic adults: a meta-analysis. Mycology 9, 116-128. doi: 10.1080/ 21501203.2017.1421592

Lee, W., and Lee, D. G. (2018). A novel mechanism of fluconazole: fungicidal activity through dose-dependent apoptotic responses in Candida albicans. Microbiology 164, 194-204. doi: 10.1099/mic.0.000589

Leon, V. (2000). Synthesis, Characterization and Catalytic and Biological Activity of New Manganese (II) Carboxylate Complexes. Ph.D. thesis, Dublin Institute of Technology, Dublin.

Maurer, E., Browne, N., Surlis, C., Jukic, E., Moser, P., Kavanagh, K., et al. (2015). Galleria mellonella as a host model to study Aspergillus terreus virulence and amphotericin B resistance. Virulence 6, 591-598. doi: 10.1080/21505594.2015

McCann, M., Coyle, B., McKay, S., McCormack, P., Kavanagh, K., Devereux, M., et al. (2004). Synthesis and X-ray crystal structure of [Ag(phendio)2]ClO4 (phendio =1,10-phenanthroline-5,6-dione) and its effects on fungal and mammalian cells. Biometals 17, 635-645. doi: 10.1007/s10534-004-1229-5

McCann, M., Gerarthy, M., Devereux, M., O’Shea, D., Mason, J., and O’Sullivan, L. (2000). Insights into the mode of action of the anti-Candida activity of 1 , 10-phenanthroline and its metal chelates. Met. Based Drugs 7, 185-193. doi: 10.1155/MBD.2000.185

McCann, M., Kellet, A., Kavanagh, K., Devereux, M., and Santos, A. L. S. (2012). Deciphering the antimicrobial activity of phenanthroline chelators. Curr. Med. Chem. 19, 2703-2714. doi: 10.2174/092986712800609733

McCann, S., McCann, M., Casey, M. T., Devereux, M., McKee, V., McMichael, P., et al. (1997). Manganese(II) complexes of 3,6,9-trioxaundecanedioic acid (3,6,9-tddaH2): X-ray crystal structures of $[\mathrm{Mn}(3,6,9-\mathrm{tdda})(\mathrm{H} 2 \mathrm{O}) 2] .2 \mathrm{H} 2 \mathrm{O}$ and $\{[\mathrm{Mn}(3,6,9-\mathrm{tdda})(\mathrm{phen}) 2] .3 \mathrm{H} 2 \mathrm{O} . \mathrm{EtOH}\}$ n. Polyhedron 16, 4247-4252. doi: 10. 1016/s0277-5387(97)00233-7

Meletiadis, J., Antachopoulos, C., Stergiopoulo, T., Pournaras, S., Roilides, E., and Walsh, T. J. (2007). Differential fungicidal activities of amphotericin $\mathrm{B}$ and voriconazole against Aspergillus species determined by microbroth methodology. Antimicrob. Agents Chemother. 51, 3329-3337. doi: 10.1128/aac. 00345-07

Mesa-Arango, A. C., Forastiero, A., Bernal-Martínez, L., Cuenca-Estrella, M., Mellado, E., and Zaragoza, O. (2013). The non-mammalian host Galleria mellonella can be used to study the virulence of the fungal pathogen Candida tropicalis and the efficacy of antifungal drugs during infection by this pathogenic yeast. Med. Mycol. 51, 461-472. doi: 10.3109/13693786.2012.737031

Mesa-Arango, A. C., Scorzoni, L., and Zaragoza, O. (2012). It takes only one to do many jobs: amphotericin B as antifungal and immunomodulatory drug. Front. Microbiol. 3:286. doi: 10.3389/fmicb.2012.00286

Minguez, F., Chiu, M. L., Lima, J. E., Nique, R., and Prieto, J. (1994). Activity of fluconazole: postantifungal effect, effects of low concentrations and of pretreatment on the susceptibility of Candida albicans to leucocytes. J. Antimcrob. Chemother. 34, 93-100. doi: 10.1093/jac/34.1.93

Minguez, F., Lima, J. E., García, M. T., and Prieto, J. (1997). Effects of antifungal pretreatment on the susceptibility of Candida albicans to human leucocytes. Chemotherapy 43, 346-351. doi: 10.1159/000239588

Mowlds, P., Barrron, A., and Kavanagh, K. (2008). Physical stress primes the immune response of Galleria mellonella larvae to infection by Candida albicans. Microbes Infect. 10, 628-634. doi: 10.1016/j.micinf.2008.02.011

Mowlds, P., Coates, C., Renwick, J., and Kavanagh, K. (2010). Dose-dependent cellular and humoral responses in Galleria mellonella larvae following b-glucan inoculation. Microbes Infect. 12, 146-153. doi: 10.1016/j.micinf.2009. 11.004

Muro, M. D., Motta, F. A., Burger, M., Melo, A. S. A., and Dalla-Costa, L. M. (2012). Echinocandin resistance in two Candida haemulonii isolates from pediatric patients. J. Clin. Microbiol. 50, 3783-3785. doi: 10.1128/JCM.011 $36-12$
Ramos, L. S., Figueireido-Carvalho, M. H., Barbedo, L. S., Ziccardi, M., Chaves, A. L., Zancopé-Oliveira, R. M., et al. (2015). Candida haemulonii complex: species identification and antifungal susceptibility profiles of clinical isolates from Brazil. J. Antimicrob. Chemother. 70, 111-115. doi: 10.1093/jac/dku321

Roilides, E., Lyman, C. A., Filioti, J., Akpogheneta, O., Sein, T., Lamaignere, G. G., et al. (2002). Amphotericin B formulations exert additive antifungal activity in combination with pulmonary alveolar macrophages and polymorphonuclear leukocytes against Aspergillus fumigatus. Antimicrob. Agents Chemother. 46, 1974-1976. doi: 10.1128/aac.46.6.1974-1976.2002

Rossi, S. A., Trevijano-Contador, N., Scorzoni, L., Mesa-Arango, A. C., Oliveira, H. C., Werther, K., et al. (2016). Impact of resistance to fluconazole on virulence and morphological aspects of cryptococcus neoformans and cryptococcus gattii isolates. Front. Microbiol. 7:153. doi: 10.3389/fmicb.2016.00153

Sanguinetti, M., Posteraro, B., and Lass-Flörl, C. (2015). Antifungal drug resistance among Candida species: mechanisms and clinical impact. Mycoses 58(Suppl. 2), 2-13. doi: $10.1111 /$ myc. 12330

Scorzoni, L., Lucas, M. P., Mesa-Arango, A. C., Fusco-Almeida, A. M., Lozano, E., Cuenca-Estrella, M., et al. (2013). Antifungal efficacy during Candida krusei infection in non-conventional models correlates with the yeast in vitro susceptibility profile. PLoS One 8:e60047. doi: 10.1371/journal.pone.0060047

Silva, L. N., Campos-Silva, R., Ramos, L. S., Trentin, D. S., Macedo, A. J., Branquinha, M. H., et al. (2018). Virulence of Candida haemulonii complex in Galleria mellonella and efficacy of classical antifungal drugs: a comparative study with other clinically relevant non-albicans species. FEMS Yeast Res. 18:foy082. doi: 10.1093/femsyr/foy082

Tohyama, M., Kawakami, K., and Saito, A. (1996). Anticryptococcal effect of amphotericin B is mediated through macrophage production of nitric oxide. Antimicrob. Agents Chemother. 40, 1919-1923. doi: 10.1128/aac.40.8.1919

Van Uden, N., and Kolipinski, M. C. (1962). Torulopsis haemulonii nov. spec., a yeast from the Atlantic ocean. Antonie Van Leeuwenhoek 28, 78-80. doi: $10.1007 / \mathrm{bf02538724}$

Venisse, N., Grégoire, N., Marliat, M., and Couet, W. (2008). Mechanismbased pharmacokinetic-pharmacodynamic models of in vitro fungistatic and fungicidal effects against Candida albicans. Antimicrob. Agents Chemother. 52, 937-943. doi: 10.1128/AAC.01030-07

Wang, Y., Li, D. D., Jiang, Y. Y., and Mylonakis, E. (2013). Utility of insects for studying human pathogens and evaluating new antimicrobial agents. Adv. Biochem. Eng. Biotechnol. 135, 1-25. doi: 10.1007/10_20 13_194

World Health Organization (2014). Antimicrobial Resistance: Global Report on Surveillance 2014. Geneva: World Health Organization.

World Health Organization (2019). Global Antimicrobial Resistance Surveillance System (GLASS) Report: Early Implementation 2017-2018. Geneva: World Health Organization.

Wu, G., Xu, L., and Yi, Y. (2016). Galleria mellonella larvae are capable of sensing the extent of priming agent and mounting proportional cellular and humoral immune responses. Immunol. Lett. 174, 45-52. doi: 10.1016/j.imlet.2016. 04.013

Conflict of Interest: The authors declare that the research was conducted in the absence of any commercial or financial relationships that could be construed as a potential conflict of interest.

Copyright (c) 2020 Gandra, McCarron, Viganor, Fernandes, Kavanagh, McCann, Branquinha, Santos, Howe and Devereux. This is an open-access article distributed under the terms of the Creative Commons Attribution License (CC BY). The use, distribution or reproduction in other forums is permitted, provided the original author(s) and the copyright owner(s) are credited and that the original publication in this journal is cited, in accordance with accepted academic practice. No use, distribution or reproduction is permitted which does not comply with these terms. 